\title{
SISTEMA DE INFORMAÇÃO GEOGRÁFICA (SIG) APLICADO A GESTÃO DE RECURSOS NATURAIS. ATLAS DO APROVEITAMENTO DE ÁGUA DA CHUVA NAS ILHAS DE BELÉM - INICIATIVAS, DEMANDAS E POTENCIALIDADES
}

\author{
GEOGRAPHICAL INFORMATION SYSTEM (GIS) APPLIED TO THE MANAGEMENT OF NATURAL RESOURCES. \\ ATLAS OF THE USE OF RAIN WATER IN THE BELÉM ISLANDS - INITIATIVES, DEMANDS AND \\ POTENTIALITIES
}

\author{
Robson Raposo Macedo ${ }^{1}$, Ronaldo Lopes Rodrigues Mendes ${ }^{1}$, Tony Costa ${ }^{1}$ \\ ${ }^{1}$ Universidade Federal do Pará (UFPA), Belém, PA, Brasil
}

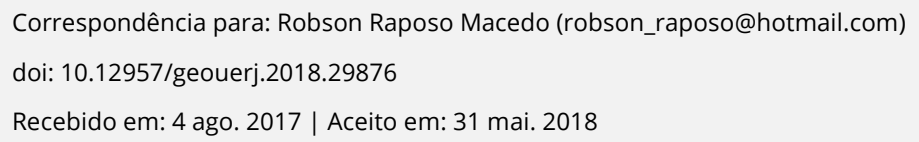

\section{RESUMO}

Essa pesquisa apresenta um estudo multidisciplinar sobre gestão de águas nas ilhas de Belém. Destaca por meio de um diagnóstico temático socioambiental experiências ribeirinhas na utilização de projetos de captação de água de chuva. Com a utilização de Sistema de Informação Geográfica (SIG), apresenta a sistematização dados e informações considerando aspectos diversos relacionados ao uso do recurso natural água em seis projetos de captação de água de chuva distribuídos em nove ilhas da cidade de Belém. Em um universo de aproximadamente 3.000 habitantes sem serviços públicos de saneamento básico, destaca ações alinhadas, conscientemente ou não, à Política Nacional de Recursos Hídricos e aos objetivos e diretrizes propostos no Plano Diretor Municipal de Belém. O produto final dessa pesquisa trata-se do resultado de uma dissertação de mestrado do Programa de Pós-Graduação do Núcleo de Meio Ambiente da Universidade Federal do Pará (NUMA/UFPA) onde se propõem o uso de um Atlas como ferramenta de auxilio à gestão ambiental, demonstrando como o uso de SIG por meio do Atlas pode contribuir na gestão de recursos naturais nas diversas temáticas que envolvem o uso de tecnologias sociais na busca de sustentabilidade e desenvolvimento local no que se refere ao uso da água em Belém.

Palavras-chave: Belém; Água de chuva; Sistema de Informação Geográfica (SIG); Gestão Ambiental; Tecnologia social.

\begin{abstract}
This research presents a multidisciplinary study on water management in the islands of Belém. It emphasizes by means of a thematic socio-environmental diagnosis riverside experiences in the use of rainwater harvesting projects. With the use of Geographic Information System (GIS), it presents the systematization of data and information considering various aspects related to the use of the natural water resource in six rainwater harvesting projects distributed in nine islands of the city of Belém. Approximately 3,000 inhabitants without basic sanitation services, highlights actions aligned, consciously or not, to the National Water Resources Policy and the objectives and guidelines proposed in the Municipal Master Plan of Belém. The final product of this research is the result of a dissertation Of the Environmental Nucleus of the Federal University of Pará (NUMA / UFPA), where they propose the use of an Atlas as a tool to assist environmental management, demonstrating how the use of GIS through the Atlas can Contribute to the management of natural resources in the various themes that involve the use of social technologies in The search for sustainability and local development regarding the use of water in Belém.
\end{abstract}

Keywords: Belém; Rainwater; Geographic Information System (GIS); Environmental management; Social technology.

\section{INTRODUÇÃO}


O aproveitamento de água da chuva permeia diversas questões ligadas à gestão sustentável de recursos naturais e desenvolvimento local, seja no aspecto do consumo humano ou na utilização dessa água em processos industriais, o uso sustentável da água sempre estará na pauta de discussão sobre o uso racional dos recursos naturais disponíveis. Refletindo sobre a garantia de qualidade de vida a todos os cidadãos segundo a ótica do Art. 225 da Constituição Federal de 1988, o acesso à água revela-se fator primordial na obtenção de condições favoráveis a sobrevivência, desenvolvimento de atividades produtivas e qualidade de vida, nesse contexto o acesso à água torna-se também uma questão de cidadania. No Brasil, um país de dimensões continentais, a água da chuva está associada a um contexto de escassez e abundância de água em meio à falta de potabilidade da água disponível. Assim, essa pesquisa visa contribuir com o desenvolvimento local a partir de uma discussão sobre as iniciativas de uso da água de chuva associadas a tratativas de gestão sustentável do recurso natural água a partir do uso de Sistema de Informação Geográfica (SIG) como ferramenta capaz de processar dados e informação econômica, social e cultural da região amazônica mais especificamente na região insular de Belém.

Essa pesquisa busca fomentar a gestão sustentável do recurso natural água no contexto da população local, propondo a utilização de um Atlas para conhecimento e acompanhamento de iniciativas de aproveitamento de água de chuva. O Atlas das iniciativas de aproveitamento de água de chuva foi idealizado a fim de propor uma análise holística a respeito dos vários fatores que exercem influência sobre o uso das águas nas ilhas de Belém. Para tanto, foi realizada a coleta documental e análise de conteúdo sobre produções acadêmicas relacionadas ao uso de água de chuva em ilhas de Belém. O levantamento de informações sobre a área de pesquisa considerou o uso de geotecnologias para processamento e caracterização de dados socioambientais que tiveram como principal fonte os dados do CENSO demográfico do Instituto Brasileiro de Geografia e Estatística (IBGE), da Companhia de Desenvolvimento e Administração da Área Metropolitana de Belém (CODEM), Plano Diretor municipal de Belém, assim como, imagens espaciais fornecidas pelo Sistema de Proteção Amazônia (SIPAM) e Instituto Nacional de Pesquisas Espaciais (INPE). 
Com a utilização de formulários de entrevista foi conhecida a dinâmica de uso das águas disponíveis à população ribeirinha, assim como a caracterização das condições socioambientais da área de pesquisa. A utilização de sistema de posicionamento global GPS (Global Positioning System), permitiu o georreferenciamento dos dados coletados possibilitando assim, a estruturação de um bando de dados em SIG. Assim, por meio do método Coroplético ${ }^{1}$ foram feitas associações cartográficas entre os dados levantados em campo e dados oficiais disponíveis. A análise da qualidade da água consumida pelos ribeirinhos foi realizada por meio de uma parceria com o Instituto Evandro Chagas (IEC). As mostras coletadas foram analisadas pela equipe de meio ambiente do IEC o que proporcionou a comparação dos parâmetros analisados com os limites estabelecidos para o consumo de água segundo a legislação brasileira.

\section{DISPONIBILIDADE HÍDRICA AMAZÔNICA E OS AVANÇOS NO USO DA ÁGUA DE CHUVA}

O aproveitamento da água da chuva para abastecimento em áreas rurais e urbanas no estuário amazônico pode parecer sem sentido, considerando localizar-se na maior bacia hidrográfica do mundo. Realmente a disponibilidade de água está entre as maiores do planeta, onde a Amazônia possui cerca 9,7\% dos recursos hídricos do planeta. O Estado do Pará está inserido na bacia amazônica, a qual ocupa uma área que se estende por mais de $6.106 \mathrm{~km}^{2}$, que de sua nascente no Perú à sua foz no oceano Atlântico percorre 7.100 km, ocupando parte de 8 países sul-americanos (Brasil, Bolívia, Colômbia, Equador, Guiana, Peru, Suriname e Venezuela); com uma vazão média na foz de 209.000 $\mathrm{m}^{3} / \mathrm{s}$ da qual $62 \%\left(129.000 \mathrm{~m}^{3} / \mathrm{s}\right)$ é gerada no Brasil, representando $72 \%$ da produção hídrica brasileira, escoando $15 \%$ do deflúvio médio mundial (. A mais alta produtividade hídrica do continente (992,6 mm/ano), com velocidades de escoamento de 0,7 a $1,9 \mathrm{~m} / \mathrm{s}$ e descargas entre 21.500 e $286.000 \mathrm{~m}^{3} / \mathrm{s}$, em Óbidos (LIMA, 2001; FILIZOLA, 2001.).

\footnotetext{
${ }^{1}$ A técnica coroplética consiste em um método de representação cartográfica que tem como finalidade traduzir valores para as áreas. Esse método foi amplamente utilizado por cartógrafos e geógrafos a partir do século XIX, por apresentar fácil assimilação por parte do usuário (MARTINELLI, 2003)
} 
Em populações rurais localizadas as margens dos principais rios do Pará (Tocantins, Xingu, Tapajós, Capim e o próprio Amazonas), que utilizam como fonte principal de abastecimento doméstico água superficial in natura ou água subterrânea de poços rasos, a opção pela água superficial tem sido associada à filtração por panos ou filtros de cerâmicos. Essa prática tem tornado essas populações passíveis de contaminação microbiológica, muito comumente associado à população bovina estadual que apresenta aproximadamente 18 a 20 milhões de cabeças (quase 3 bois/humano, considerando a população do estado do Pará em 18.262.547 em 2011) ou mesmo por fezes humanas, já que estas regiões ribeirinhas não apresentam formas adequadas de disposição de seu esgoto, muito frequentemente lançados no próprio corpo receptor utilizado para captação de água para consumo humano.

A contaminação por esgoto sanitário é fonte de contaminação também de poços rasos às proximidades das fossas negras. A água subterrânea apresenta ainda como limitação em áreas de várzea a contaminação superficial (jusante da Barragem de Tucurui no rio Tocantins e na foz do rio Amazonas, que se estende além das cidades de Belém e Macapá); nessas áreas se observa solos argilosos orgânicos com profundidade de 20 a $80 \mathrm{~m}$, isso implica na necessidade de poços com profundidades maiores que $80 \mathrm{~m}$, pois a captação acima de $20 \mathrm{~m}$ está sujeita a contaminação superficial. Nesse caso o poço seria a solução, mas considerando a frequente precariedade financeira das comunidades locais, os custos de implantação de poços profundos são impeditivos para instalação em unidades unifamiliares e comunitárias (MENDES, 2012).

As regiões de entorno dos principais rios do estado do Pará apresentam pluviometria anual superior à $2.000 \mathrm{~mm}$, enquanto que, no município de Belém, área definida para estudo, observa-se média anual, nos últimos 100 anos entre 2.000 e $3.000 \mathrm{~mm}$. No entanto, esta água é lançada diretamente sobre os terrenos alimentando os aquíferos, a biota, igarapés, rios e baías o que embora cumpra seu papel dentro do ciclo hidrológico, nos remete a possibilidade de sua utilização no abastecimento das diversas comunidades que não possuem nenhum tipo de programa para abastecimento e que muitas vezes precisam se deslocar por longas distâncias para obter água de melhor qualidade do que aquela que as circundam (MENDES, 2009; EMBRAPA, 2001). 
A questão principal a ser observada é que grandes volumes de água doce não garantem qualidade de água para determinado fim, como por exemplo, o consumo humano, o qual deve atender a parâmetros rigorosos de concentrações de massa e energia por unidade de volume, conforme definido pelo Ministério da Saúde (2012), que define os parâmetros de potabilidade da água no Brasil. Por isso, as condições de abastecimento de água potável nas regiões do estuário amazônico têm sido eivadas de severos problemas. Cerca de $12 \%$ da população urbana de Belém não é atendida por água encanada (AMAE, 2014). Nas áreas rurais esta situação é ainda pior. A saída mais comum é o uso da água dos igarapés e rios, o que implica muitas vezes em comprometimento da saúde das populações destas localidades. Rebolças (2004) ressalta que o problema de abastecimento de água no Brasil está pautado no quadro de pobreza endêmica que atinge a maior parte da sua população que não pode pagar pelo serviço de captação, transporte, tratamento e distribuição da água limpa para consumo humano.

Com base no exposto acima, a captação de água da chuva constitui-se uma alternativa que deve ser avaliada como forma de contribuir para a melhoria da qualidade de vida com uso adequado dos recursos hídricos disponíveis às regiões situadas nas margens dos rios amazônicos. Considerando a distribuição geográfica da região cabe a reflexão sobre a necessidade de gestão integrada de projetos de aproveitamento de água da chuva com utilização de ferramentas que possibilitem a visualização simultânea das particularidades das populações locais. Essa questão não envolve somente acesso a informação, mas também, a validade das informações. Segundo Kinoshita (1999) a questão da sustentabilidade na Amazônia se desenvolve no conflito dos discursos do meio acadêmico, dos organismos de desenvolvimento regional e a da sociedade civil.

\section{Instrumentos de Gestão de Recursos Hídricos para a cidade de Belém e o uso da água de chuva}

Na cidade de Belém, no ano de 2004 o Plano Diretor do Sistema de Abastecimento de Água da Região Metropolitana de Belém-PA surge como um dos principais instrumentos de gestão de recursos hídricos, porém em sua elaboração, considerou apenas quatro alternativas de concepção de Sistemas de Abastecimento de Águas (SAA) para a Região Metropolitana de Belém (RMB), todas elas adotando a 
utilização de água proveniente de manancial superficial e subterrâneo. Em se tratando do uso da água da chuva, a nível estadual, somente no ano de 2008, a partir do Decreto nํㅜ 1.367 de 29/10/2008, no Estado do Para, a água de chuva começa a tomar espaço no viés legislativo considerando a água de chuva como recurso hídrico meteórico dentre os superficiais, subterrâneos e emergentes ou em depósito, mas que no Art. $5^{\circ}$ não considera a captação humana antes dessa água escoar como água superficial em riachos e rios até se infiltrar na terra abastecendo o lençol de água subterrânea.

Os planos até então estabelecidos consideram formas de abastecimento que não atenderam as populações ribeirinhas, o que levou a necessidades de novas discussões quanto aos modelos de gestão e desenvolvimento a serem adotados para o município. O entendimento sobre desenvolvimento local permeia a forma de apropriação dos recursos naturais e as dinâmicas de ordenamento de um território. No recorte do território ocorre uma organização complexa que vai além dos atributos naturais e ultrapassa a visão de custos de transporte e de comunicação. (ABRAMOVAY, 2000).

Assim, o desenvolvimento local está relacionado à busca pelo bem estar social ditando regras de formulação e reformulação das organizações sociais e recortes territoriais. Os estudos sobre o desenvolvimento são entendidos como a análise das condições capazes de favorecer o progresso e 0 bem estar humano (SATUSTREGUI, 2013). Nesse aspecto os modelos de desenvolvimento podem ser contraditórios as perspectivas locais se não internalizarem as dinâmicas sociais desenvolvidas por meio da interação socioambiental local.

Por meio da Lei № 8.655, de 30 de julho de 2008, a cidade de Belém obtém mais um instrumento de gestão para o município o Plano Diretor do Municipal. Com o objetivo de promover o desenvolvimento da cidade, com justiça social, melhoria das condições de vida de seus habitantes e usuários, e desenvolvimento das atividades econômicas o plano diretor por meio do art. 79 divide o município em Macrozona do Ambiente Urbano (MZAU) e Macrozona do Ambiente Natural (MZAN), as quais definem o ordenamento do território municipal, tendo como referência as características do ambiente urbano e natural. (Figura 1) 
A Macrozona do Ambiente Urbano (MZAU) corresponde às áreas urbanizadas do território, situandose predominantemente na porção continental e em parte das ilhas de Caratateua, Mosqueiro e Cotijuba. A Macrozona do Ambiente Natural (MZAN) corresponde às áreas não urbanizadas das ilhas de Caratateua, Mosqueiro e Cotijuba, às demais ilhas do Município em sua totalidade, e a Área de Proteção Ambiental dos Mananciais de Abastecimento de Água de Belém (APA-Belém). A cidade de Belém possui um total de 39 ilhas, um percentual de 65\% do território da capital paraense, em número absolutos, juntas essas ilhas formam uma superfície de 32.993,61 hectares (BELÉM, 2011).

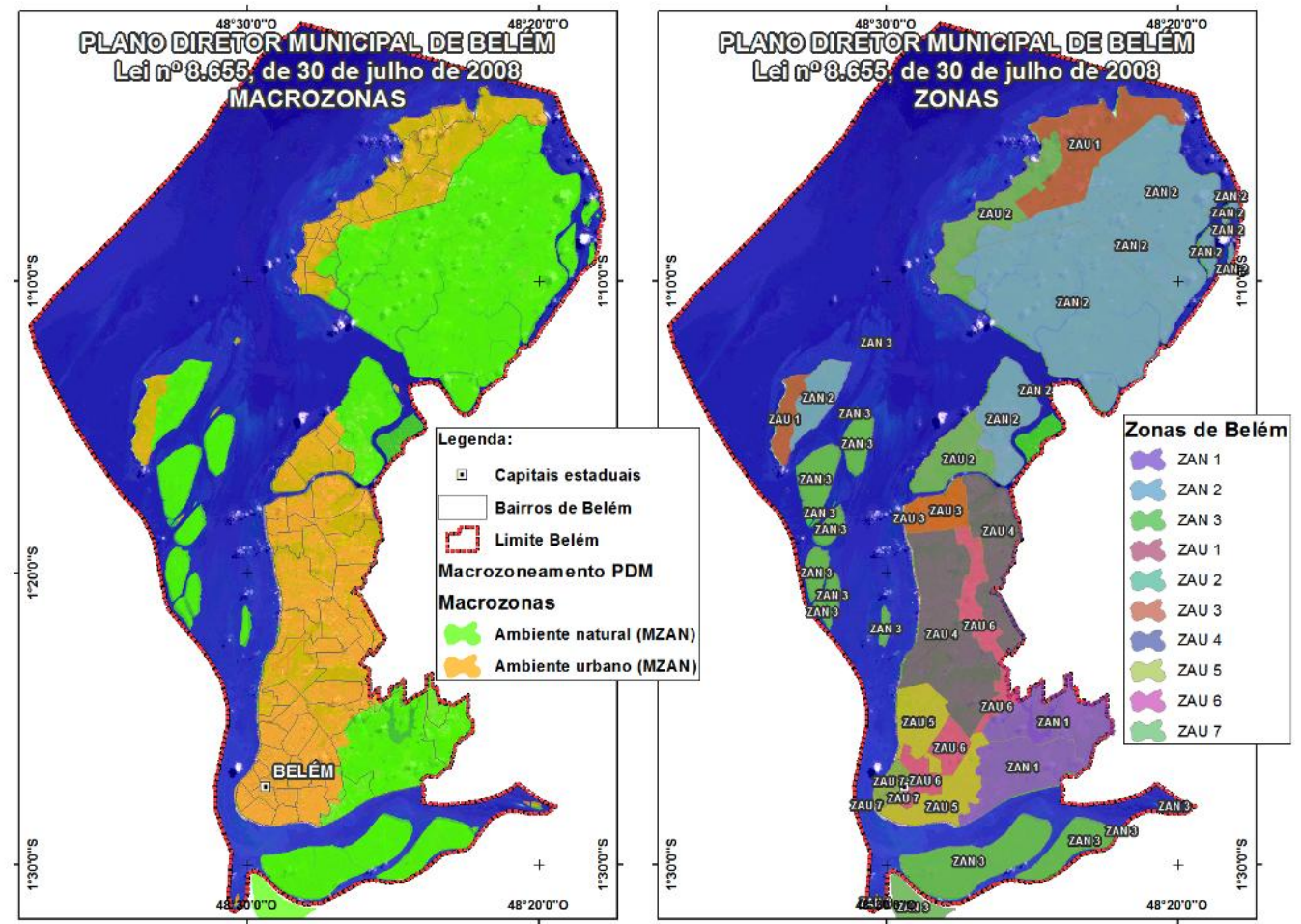

Figura 1. Macrozoneamento e zoneamento de Belém segundo Plano Diretor Municipal. Fonte: Adaptado do Plano Diretor Municipal de Belém

Nesse contexto a cidade de Belém mostra um avanço significativo quanto ao planejamento do território a partir da definição de zonas de gerenciamento. Em se tratando da gestão de recursos hídricos em 2014, o Plano Municipal de Saneamento Básico de Abastecimento de Água e Esgotamento Sanitário de Belém apresenta uma mudança quanto a gestão de águas das ilhas. Trás em seu escopo uma breve discussão sobre o abastecimento de água nas ilhas feito através de tecnologias alternativas individuais mostrando como inovações alternativas a captação de água de chuva em áreas que segundo o Plano 
diretor municipal de 2008 observa como Zona do Ambiente Natural 3 (ZAN 3), caracterizadas como áreas de várzea, com existência de comunidades ribeirinhas e sem formação de núcleos urbanos.

A dinâmica local das ilhas sugere um novo desafio aos projetos de desenvolvimento local quando voltados ao fornecimento de água potável a população ribeirinha. Nesse contexto A água de chuva é considerada uma fonte alternativa de abastecimento. Segundo Mesquita (2012), ao estudar a qualidade da água consumida em Mosqueiro (Ilha de Belém) observou que o risco à saúde da população estava associado à falta do sistema de abastecimento de água, pois nos estudos realizados foi encontrado um maior percentual de coliformes totais e Escherichia coli, em áreas onde o abastecimento de água era feito por poços particulares.

Segundo Mendes (2012), os sistemas de abastecimentos de água de atendem a cidade de Belém não cobrem a área das ilhas distribuídas à Oeste e ao Sul de Belém. Uma área abundante em água, ilhas banhadas pelo Rio Guamá e Baia do Guajará. Áreas que segundo o Censo IBGE do ano de 2010 é constituída por uma população de 3.049 pessoas.

\section{ÁGUA DE CHUVA COMO SISTEMA ALTERNATIVO DE ABASTECIMENTO}

Não é cidadão alguém que depende de um político até para beber um copo d'água. A cisterna, sozinha, não dá essa independência às pessoas, mas sinaliza o rumo da caminhada (MALVEZZI, 2007, p, 16.). A água de chuva é, e deve ser considerada uma fonte alternativa de abastecimento. De acordo com Gonçalves (2012), a temática de aproveitamento de água de chuva se enquadra no campo da conservação das águas em geral. O aproveitamento de águas de fontes alternativas vem sendo estudado por diversos seguimentos da sociedade moderna e com evoluir dos estudos aplicados, tecnologias têm sido desenvolvidas na busca do maior e melhor uso do potencial de abastecimento das águas pluviais.

O uso de águas de chuva não é novidade para a humanidade, porém o surgimento de novas tecnologias e um novo perfil de gestão ambiental tem proporcionado novas formas desse recurso natural 
disponível. A água de chuva pode ser utilizada para diversos fins como na descarga de vasos sanitários, serviços de limpeza, irrigação, reservatório contra incêndio, dessedentação de animais, lazer, e etc.

A compreensão de tecnologias de aproveitamento de água necessariamente deve passar pelo crivo do raciocínio de ordem metodológica. Mas além das questões de ordem geográficas, físicas, químicas e biológicas deverão ser consideradas questões sociológicas. No contexto geográfico do aproveitamento de água da chuva o debate parece relevante só quando em região de secas. Porém, o contexto amazônico é caracterizado pela riqueza hídrica, assim, a abordagem sociológica do aproveitamento da água da chuva será consequência da expertise, do grupo social a se debruçar sobre essa temática. A análise sociológica mostra que a competência de cada grupo social é indissociavelmente uma competência técnica e social, ou seja, ser capaz de ou se julgar ou sentir habilitado para. (CHAMPAGNE, 1998).

A promoção de programas de aproveitamento de água da chuva também tem sido uma realidade em países como China, Nova Zelândia e Tailândia especialmente em áreas rurais, onde o armazenamento de água da chuva é por meio de sistema de calhas acoplado aos telhados sendo essa a solução de regiões onde o acesso à água é limitado. A China com o esgotamento de várias fontes de água tomou a iniciativa de reaproveitar tanques de armazenamento de águas pluviais. Essa técnica era utilizada pelos chineses há séculos, mas, em um determinado momento optou pelas redes de abastecimento de águas captadas em rios e açudes, prática que levou ao esgotamento dos mananciais. (ZOLET, 2005) A necessidade de uso sustentável das águas levou a sociedade a ampliar a ótica no que se trata da regulação do uso dos recursos hídricos disponíveis, abrindo espaço no ambiente amazônico - conhecido mundialmente - pela abundância de água doce para o aproveitamento da água da chuva para consumo humano. 0 aproveitamento da água da chuva num cenário de escassez de água doce não é novidade, muito menos a discussão sobre assunto; como exemplificado por Tomaz (2003) ao citar o caso de reservatórios escavados no Oriente Médio e a Pedra Moabita, reservatórios de captação da água da chuva há 850 a.C. 
Hoje, existem inúmeras ações no sentido de avaliar os problemas de escassez de água que a população sofre. Pode-se citar o Programa Um Milhão de Cisterna, P1MC, capitaneado pela Articulação do Semiárido Brasileiro - ASA. Desde seu surgimento, em 2003, até março de 2014, o P1MC construiu 523. 654 cisternas, beneficiando mais de 2 milhões e 250 mil pessoas.

Considerando o uso da água de chuva como opção de sistema de abastecimento sabe-se que somente as primeiras águas carreiam ácidos, microorganismos, e outros poluentes atmosféricos. Normalmente, pouco tempo após o início da chuva, a mesma já adquire características de água destilada, que pode ser coletada em reservatórios fechados. (VIDAL, 2002).

\section{GESTÃO DA INFORMAÇÃO E OS SISTEMAS DE INFORMAÇÃO GEOGRÁFICA (SIG)}

\section{Sistemas de Informação Geográfica (SIG) como ferramenta de gestão}

Os sistemas de informações geográficas foram idealizados e desenvolvidos como uma tecnologia voltada a gestão da informação que faz uso de entidades distribuídas geograficamente em grandes extensões territoriais. Segundo Oliveira (2013), os sistemas de informações geográficas podem ajudar no aprimoramento dos processos de tomada de decisão a partir da representação das informações disponibilizadas na base de informações, apresentada em mapas geográficos temáticos. Essa compreensão sobre as funcionalidades de SIG's permite que o processo de observação de problemática, o pesquisador possa elencar questões relevantes na concepção de hipóteses. O benefício proposto pela utilização de SIG traz em sua raiz a utilização de metodologia de análise embutida nas regras de negócio do programa. Ou seja, a combinação de variáveis, em experimentação, pode levar o pesquisador a ratificar ou refutar uma hipótese pré-estabelecida.

Essas características tornam os sistemas de informação georreferenciadas um novo instrumento para a gestão ambiental e o manejo de recursos naturais. Um SIG pode ser alimentado por informações de diversas fontes, empregando tecnologias como digitalização de mapas, aerofogrametria, sensoriamento remoto, levantamento de campo e outros (RODRIGUES, 1990). Para Costa (2012) um Sistema de 
Informações Geográficas (SIG) pode ser utilizado como poderosa ferramenta de armazenamento de dados para a "análise de risco, análise de distribuição de fenômenos e de planejamento espacial". No mesmo entendimento o SIG pode atuar no processo de tomada de decisões onde as decisões devem ser tomadas a partir da adequação de fatores segundo o contexto analisado. Esses fatores podem ser ambientais, políticos e socioeconômicos, os mesmos podem ser agregados a um banco de dados consistente e por meio dele torna-se possível o processo de análise da problemática em questão.

Para Davis \& Câmara (2001) o SIG é um sistema que realiza o tratamento computacional de dados geográficos, que além de dados de características alfanuméricas, também através da localização geográfica oferece ao gestor a possibilidade de inter-relacionar as mais variadas informações associadas a uma localização geográfica. Marcelino (2003) retrata a evolução a qual as geotecnologias (SIG, GPS, sensoriamento remoto, etc.) vêm sofrendo ao longo dos últimos anos, principalmente no mapeamento de áreas de risco das grandes e médias cidades. Essa evolução é baseada na coleta de dados das características físicas e sociais das áreas de ocorrências de acidentes ou de risco que agregadas em um banco de dados georreferenciado proporciona melhor cenário para o planejamento urbano.

Nesse sentido os projetos de aproveitamento da água da chuva devem levar em consideração as características locacionais. De acordo com o Righetto (2009), quando analisa os projetos de abastecimento do Programa de Pesquisas em Saneamento Básico (PROSAB), um fator importante no dimensionamento de um sistema de aproveitamento de águas pluviais é a demanda que se pretende atender. Em Belém foi desenvolvida a avaliação do aproveitamento sustentável da água da chuva para fins potáveis de abastecimento nas ilhas Grande e Murutucu, como forma de promover o desenvolvimento local sustentável. (VELOSO, 2012).

\section{O uso de Geoprocessamento na cartografia}

O Geoprocessamento em sua essência utiliza técnicas matemáticas e computacionais para processamento da informação geográfica. As técnicas de análise de dados a partir do uso de 
ferramentas de geoprocessamento têm influenciado cada vez mais os diversos campos de pesquisa a recorrer as áreas de Cartografia para melhor compreensão do seu território de pesquisa. Os sistemas de informações geográficas fazem parte do rol de ferramentas computacionais utilizados no geoprocessamento, a utilização dessa ferramenta permite a integração de dados diversos e organização desses dados em um banco de dados georreferenciado o que, também, proporciona a realização de análises complexas considerando as peculiaridades da área de estudo (CASANOVA, 2005).

Segundo Câmara (1996) o geoprocessamento é um conjunto de conhecimentos e técnicas computacionais utilizados no processamento de informações geográficas. Um dos objetivos mais evidentes no geoprocessamento é o processamento de dados georreferenciados, por meio de tecnologias que envolvem coleta e tratamento de informações espaciais, buscando uma representação simplificada do mundo real e generalizando suas características e relações para um objetivo específico (MEDEIROS, 1999).

\section{PROPOSTA DE UTILIZAÇÃO DO ATLAS DE USO DE ÁGUA DE CHUVA COMO FERRAMENTA DE AUXÍLIO AOS PROCESSOS DE GESTÃO VINCULADOS AOS INSTRUMENTOS DE GESTÃO DE RECURSOS HÍDRICOS}

A história dos atlas está vinculada, de forma simplista, a necessidade de melhor agrupar mapas. Em outras palavras os atlas eram usados apenas para facilitar o uso de mapas. Registros históricos revelam que o início da utilização de atlas na cartografia se deu por meio do uso de enciclopédias, no geral eram constituídos por mapas históricos e geográficos. Reconhecido como o primeiro registro histórico de uso de um atlas, a obra "Geografhia", de Ptolomeu, datada do século II, apresenta em anexo um atlas que objetivava o conhecimento do mundo e a localização de lugares. (MACHADO, 2012).

A partir do século XV, era do Renascimento, em meio a invenção de novas possibilidades de gravação de registros cartográficos, os atlas deixam de ser uma mera ferramenta de agrupamento de mapas e passa a ser concebido em construto intelectual. O primeiro Atlas considerado como moderno foi o de 
Abraham Ortelius intitulado "Theatrum Orbis Terrarum" de 1570. Segue-se a este "Speculum Orbis Terrarum" de Gerard de Jode, de 1578, o "Mercator" de Gerhardt Kremer, de 1595, intitulado "Atlas Sive Cosmographicae Meditationes de Fabrica Mundi et Fabricat Figura" onde pela primeira vez se usou o termo "Atlas".

Em território europeu, no século XVII, por meio do "Projet d'une dime royale", em tratado econômico, o marechal Vauban propôs um "Atlas da França" (1698). A ideia era dar destaque ao que havia de mais importante no território francês, por esse trabalho se dá a Vauban o mérito de inventor dos Atlas nacionais e regionais. (LIBAULT, 1967 in MACHADO, 2012). Na Alemanha, no início do século XIX, os Atlas geográficos surgiram como disciplina escolar no auxílio ao ensino e aprendizagem da Geografia. Os primeiros atlas foram os do editor Homann: o "Kleiner Atlas Scholasticus" de 1710 e o “Atlas methodicus" de 1719 (MARTINELLI, 2011).

Segundo Aguiar (2011), no Brasil, na cidade do Rio de Janeiro, o uso de atlas no contexto do ensino surge a partir do ano de 1868 por meio do "Atlas do Império do Brasil" de Cândido Mendes de Almeida. Em 1936 a primeira versão do "Atlas geographico geral e especialmente do Brasil" da Companhia Melhoramentos de São Paulo do Padre Geraldo José Pauwels ganha destaque sendo referência no ensino da geografia no Brasil (MARTINELLI, 2011).

O conceito de atlas passa então ao processo de transformação, em 1953, atlas é "[...] uma coleção de mapas, formando geralmente um volume, publicado em um mesmo idioma, com simbolismo uniforme e idêntica projeção, mas não necessariamente na mesma escala" (RAISZ, 1953 et all MACHADO, 2012, p. 65). Para Oliveira (1988) atlas é uma coleção ordenada de mapas, com finalidade de representar um espaço dado e expor um ou vários temas. Segundo Ferreira (1999) o atlas é a "coleção de mapas ou cartas geográficas em volume" (MACHADO,2012, p. 65).

A utilização de Atlas no processo de ensino segundo Machado (2012), surge a partir da publicação do livro "Le langue des géographes" de Fronçois de Dainville em 1964, onde ocorre a adequação de mapas organizados em atlas como recursos didático-pedagógicos no ensino e aprendizagem de 
geografia. Como referência de influência mundial da utilização de atlas cita-se também o clássico "Atlas général Vidal de La Blache, histoire et géographie" de 1894. No Brasil o Atlas do Império do Brazil" de Cândido Mendes de Almeida, de 1868, foi o primeiro atlas escolar apresentado no contexto do ensino.

Segundo Menezes (2005), "organização de Atlas requer uma base cartográfica, dados confiáveis, textos informativos, mapas temáticos diversos, glossário, índice e figuras para ilustração" (MENEZES, 2005, p. 9106). Para Aguiar (1997, apud ALMEIDA, 2007, p. 7) os Atlas "foram criados com o objetivo de unir em um único documento um sistema complexo de fenômenos, fatos e eventos, tratados no contexto físico, social, político, cultural e econômico que, tradicionalmente, são representados por meios de mapas e textos".

No Brasil o Instituto de Pesquisa Econômica Aplicada (IPEA) em parceria com a Fundação João Pinheiro do Governo do Estado de Minas Gerais e o Programa das Nações Unidas para o Desenvolvimento (PNUD) desenvolveram o Atlas do Desenvolvimento Humano no Brasil que busca oferecer um panorama do desenvolvimento humano e da desigualdade interna dos municípios, estados e regiões metropolitanas. Outra experiência é o Atlas da Justiça Ambiental, uma iniciativa europeia que como um recurso didático, gestores públicos e privados, acadêmicos e outros usuários de forma geral, podem encontrar muitos usos para o banco de dados, bem como aprender mais sobre os conflitos ambientais, muitas vezes invisíveis que estão acontecendo pelo mundo. (EJATLAS.ORG, 2015).

O ATLAS do aproveitamento de água de chuva nas ilhas de Belém se constrói a partir do conhecimento de experiências diversas de uso dessa tecnologia social, trazendo ao conhecimento das instituições públicas, privadas e organizações sociais a realidade peculiar das iniciativas identificadas propondo a sociedade uma ferramenta capaz de armazenar e tonar público e acessível o conhecimento já adquirido no que se trata do aproveitamento de água da chuva na região amazônica.

\section{ÁREA DA PESQUISA}


A área de pesquisa se distribui pela região insular de Belém e abrange 9 das 39 ilhas da cidade de Belém. Localizada entre as coordenadas $01^{\circ} 02^{\prime} 30^{\prime \prime S} ; \quad 48^{\circ} 28^{\prime} 00^{\prime \prime W}$ e $01^{\circ} 29^{\prime} 30^{\prime \prime} \mathrm{S} ; \quad 48^{\circ} 28^{\prime} 00^{\prime \prime W}$ a cidade de Belém está inserida no contexto da Amazônia Legal Brasileira, é a capital do estado do Pará e economicamente uma das cidades mais importantes da maior região metropolitana da Amazônia, a Região Metropolitana de Belém (RMB). Belém é uma cidade costeira, considerando os aspectos hidrográficos, pode ser acessada pelo Rio Guamá e pela Baia do Guajará. Por Rodovia, é interligada a outros municípios por meio da BR 316 e por via aérea pelo aeroporto Internacional de Belém/Val-deCans - Júlio Cezar Ribeiro. Figura 2.

A RMB é caracterizada por um clima tropical úmido de floresta, de baixa altitude, topografia plana e vegetação densa, essa é uma região chuvosa, que segundo Bastos (2002) apresenta precipitação pluviométrica anual em torno de $3.001 \mathrm{~mm}$. O período de maior intensidade de chuvas se estende do mês de dezembro ao mês de abril, enquanto os meses de agosto a outubro são caracterizados por uma baixa pluviosidade.

Em um estudo realizado pela Empresa Brasileira de Pesquisa Agropecuária (EMBRAPA) considerando os Aspectos Climáticos de Belém nos Últimos Cem Anos, conclui-se que as chuvas em Belém são resultantes das seguintes situações:

De dezembro a maio, época mais chuvosa, a precipitação é originada pela ITCZ $^{2}$ e pelos efeitos de mesoescala, como as linhas de instabilidades que se formam na costa Atlântica da Guiana e Pará, e propagam-se para o oeste como uma linha de cumulonimbus. Estas linhas originam-se em associação à brisa marítima e se formam no período da tarde; de junho a agosto, final do período chuvoso, as chuvas são provocadas por efeitos locais, como as brisas terrestres e marítimas e por Ondas de Este, vindas nas correntes dos ventos alísios, geralmente os do sudeste. Estas ondas são fenômenos que se formam no campo da pressão atmosférica, ao longo dos alísios, na faixa tropical do globo, deslocando-se de leste para oeste (Vianelo \& Alves, 1991); de setembro a novembro, período de estiagem, a precipitação geralmente é provocada pelos fenômenos de mesoescala. (BASTOS, 2002, p. 14

Com uma população de 1.393.399 habitantes no último censo, Belém possuía uma densidade demográfica de 1.315,26 hab $/ \mathrm{km}^{2}$. Sendo a cidade mais expressiva da RMB, tem $99 \%$ de sua

${ }^{2}$ ITZ - ZCIT Zona de Convergência InterTropical (situado nas proximidades do equador, marca a zona de convergência do ar que se move das regiões subtropicais de ambos os hemisférios em direção ao equador; zona de confluência dos ventos alísios de sudeste e nordeste) 
população localizada em área urbana, um quantitativo de 1.381 .475 habitantes. A população rural é representada por uma população de aproximadamente 11.924 habitantes, apenas $1 \%$ do total de munícipes.

Considerando a distribuição geográfica das ilhas, para uma melhor compreensão da área de pesquisa, como pode ser observado no Figura 4, às ilhas foram agrupadas em dois grupos de análise. 0 grupo Ilhas Oeste, é formado pelas ilhas Longa, Jararaquinha, Nova, Paquetá, Urubuoca e Jutuba, que segundo o anuário estatístico da cidade de Belém do ano de 2007, juntas essas ilhas formam um território de $22,01 \mathrm{Km}^{2}$, área correspondente à $4 \%$ do território do município de Belém. Por sua vez 0 grupo de Ilhas ao Sul é formado pelas ilhas do Combú, Murutucu e Ilha Grande, uma área de 32,83 $\mathrm{Km}^{2}$. Na Tabela 1 é apresentado um resumo do quantitativo de área das ilhas e os agrupamentos de ilhas segundo os setores de análise

\begin{tabular}{c|lc|c}
\hline \multicolumn{1}{c|}{ Setores de análise } & \multicolumn{1}{c}{ Ilhas } & Área $\left.\mathbf{( K m}^{\mathbf{2}}\right)^{*}$ & Distância da sede em $\mathbf{K m}^{*}$ \\
\hline \multirow{2}{*}{ Ilhas Oeste } & Ilha Longa & 1,1 & 7,0 \\
& Ilha Jararaquinha & 1,9 & 6,2 \\
& Ilha Urubuoca & 3,5 & 5,2 \\
& Ilha Nova & 2,7 & 3,4 \\
& Ilha Paqueta & 7,8 & 4,4 \\
& Ilha Jutuba & 5,0 & 3,1 \\
\hline \multirow{2}{*}{ Ilhas Sul } & Ilha Grande (Paulo da Cunha) & 9,2 & 12 \\
& Ilha Murutucu & 8,7 & 9 \\
\cline { 2 - 4 } & Ilha do Combu & 14,9 & 6,3 \\
\hline
\end{tabular}

Tabela 1. Relação de ilhas por áreas de abrangência. Fonte: Anuários Estatísticos do município de Belém (CODEM,2007)

O reconhecimento geográfico espacial da área de pesquisa se iniciou com o mapeamento das ilhas com iniciativas de captação e uso da água de chuva. Para tanto, por meio do método Coroplético foram identificados e selecionados os setores censitários que no Censo do IBGE, na cidade de Belém, região insular, no ano de 2010, apresentassem pelo menos 1 domicílio com armazenamento de água de chuva em cisterna (Figura 3). A técnica coroplética consiste em um método de representação cartográfica que tem como finalidade traduzir valores para as áreas. Esse método foi amplamente utilizado por cartógrafos e geógrafos a partir do século XIX, por apresentar fácil assimilação por parte do usuário 
(MARTINELLI, 2003). A utilização dessa técnica permitiu a seleção de setores censitários nos quais foram identificadas as ilhas abordadas nessa pesquisa. A utilização de setores censitários, também permitiu a utilização dos quantitativos disponibilizados pelo IBGE.

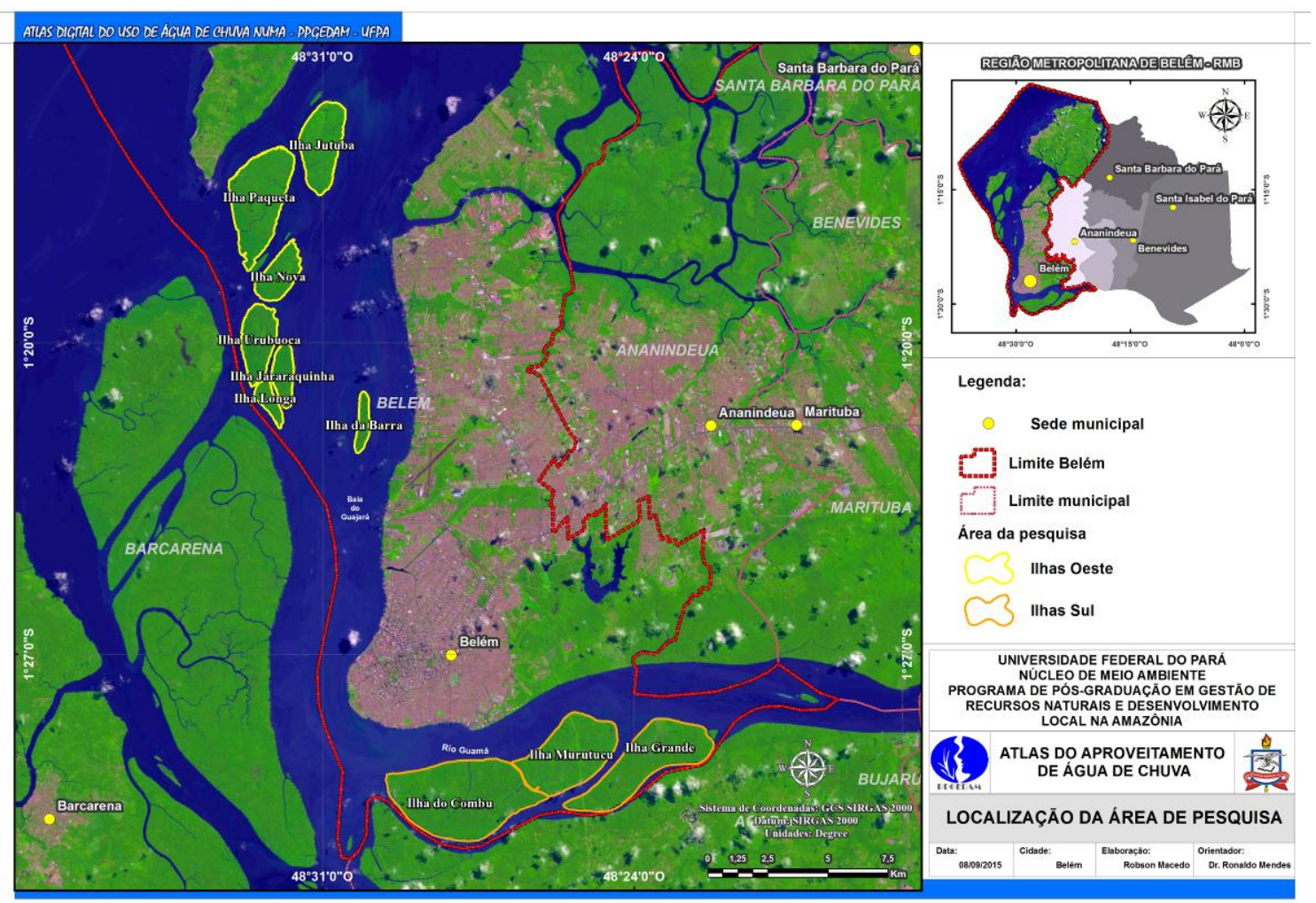

Figura 2. Localização da área de pesquisa. Fonte: Elaborado pelo autor

A partir de uma pré-localização das áreas a partir da definição de polígono (setores censitários), foi feita uma análise espacial de área, técnica que consiste na análise de dados espaciais cuja localização está associada a áreas delimitadas por polígonos. Busca-se assim a compreensão das áreas onde não se dispõe da localização exata dos eventos, porém apresentam valor por área como é o caso dos dados do censo em sobreposição ao limite das ilhas. A utilização desse método se justifica pela necessidade de localizar geograficamente os fenômenos a serem estudados.

A partir desse recorte foram selecionadas as ilhas à Oeste e ao Sul de Belém que apresentassem domicílios com armazenamento de água de chuva. Para essa pesquisa será utilizado o termo "iniciativas de aproveitamento de água de chuva" para os domicílios que fazem uso da água de chuva. As ilhas em que o IBGE identificou iniciativas de aproveitamento de água de chuva foram somadas as ilhas já selecionadas a partir da revisão da literatura e análise documental. 


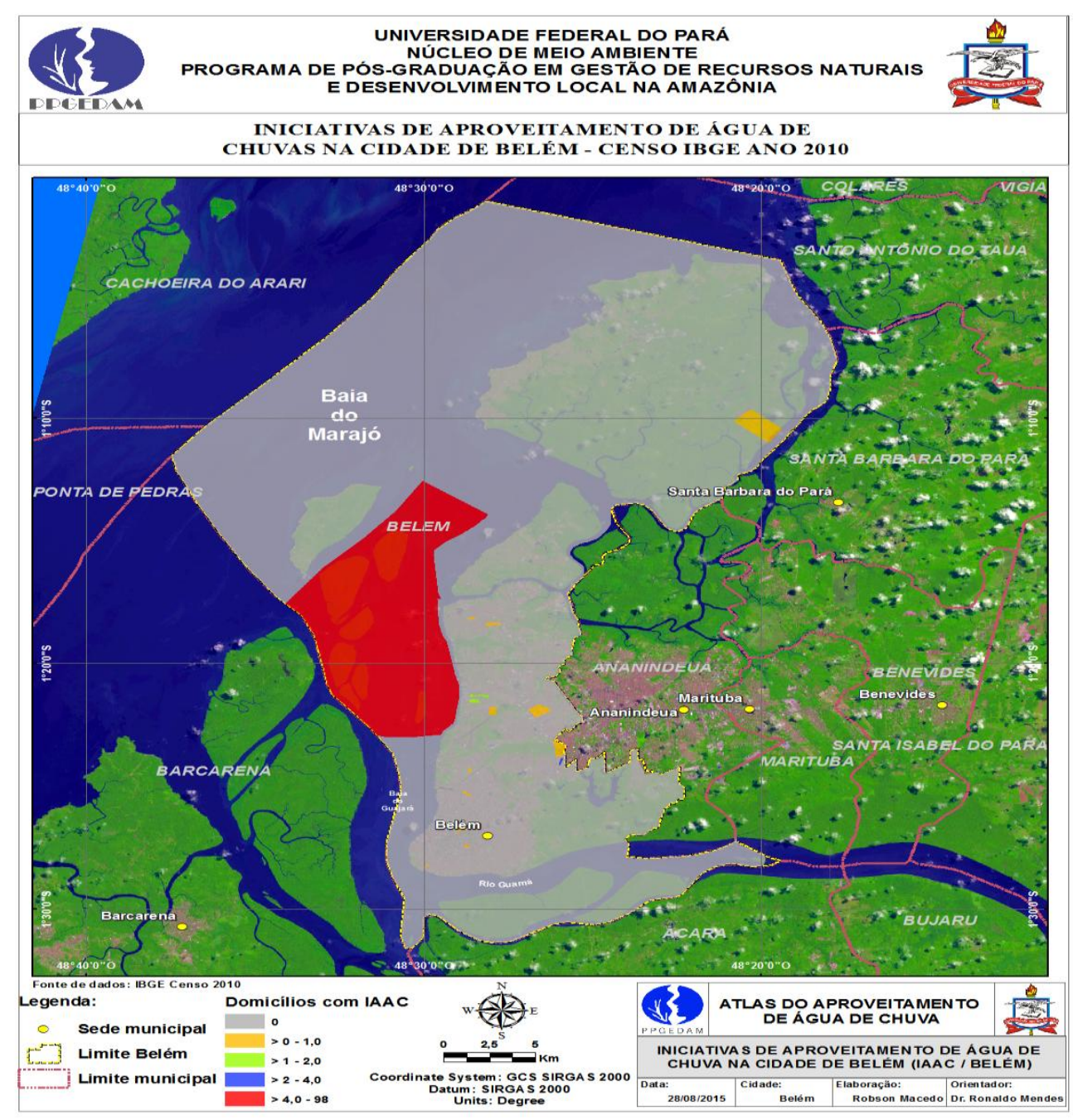

Figura 3. Localização das iniciativas de captação de água de chuva em Belém. Fonte: Elaborado pelo autor.

\section{RESULTADOS E DISCUSSÕES}

\section{Abastecimento de água nas ilhas}

A população de Belém é atendida pelas seguintes prestadoras públicas de serviços de saneamento básico: Companhia de Saneamento do Pará (COSANPA), Serviço Autônomo de Água e Esgoto de Belém (SAAEB) da Secretaria Municipal de Saneamento (SESAN). Nas ilhas tratadas nessa pesquisa nenhum desses órgãos tem atuação. Após análises geoestatísticas dos dados referentes ao censo do IBGE ano de 2010, constatou-se que o total de moradores para a área amostrada é de 3.049 moradores, dos quais 1.045 estão distribuídos na área das ilhas localizadas à Oeste e 2004 nas ilhas localizadas ao Sul de Belém, desses quantitativos 99\% moram em domicílios do tipo casa. (Figura 4). 


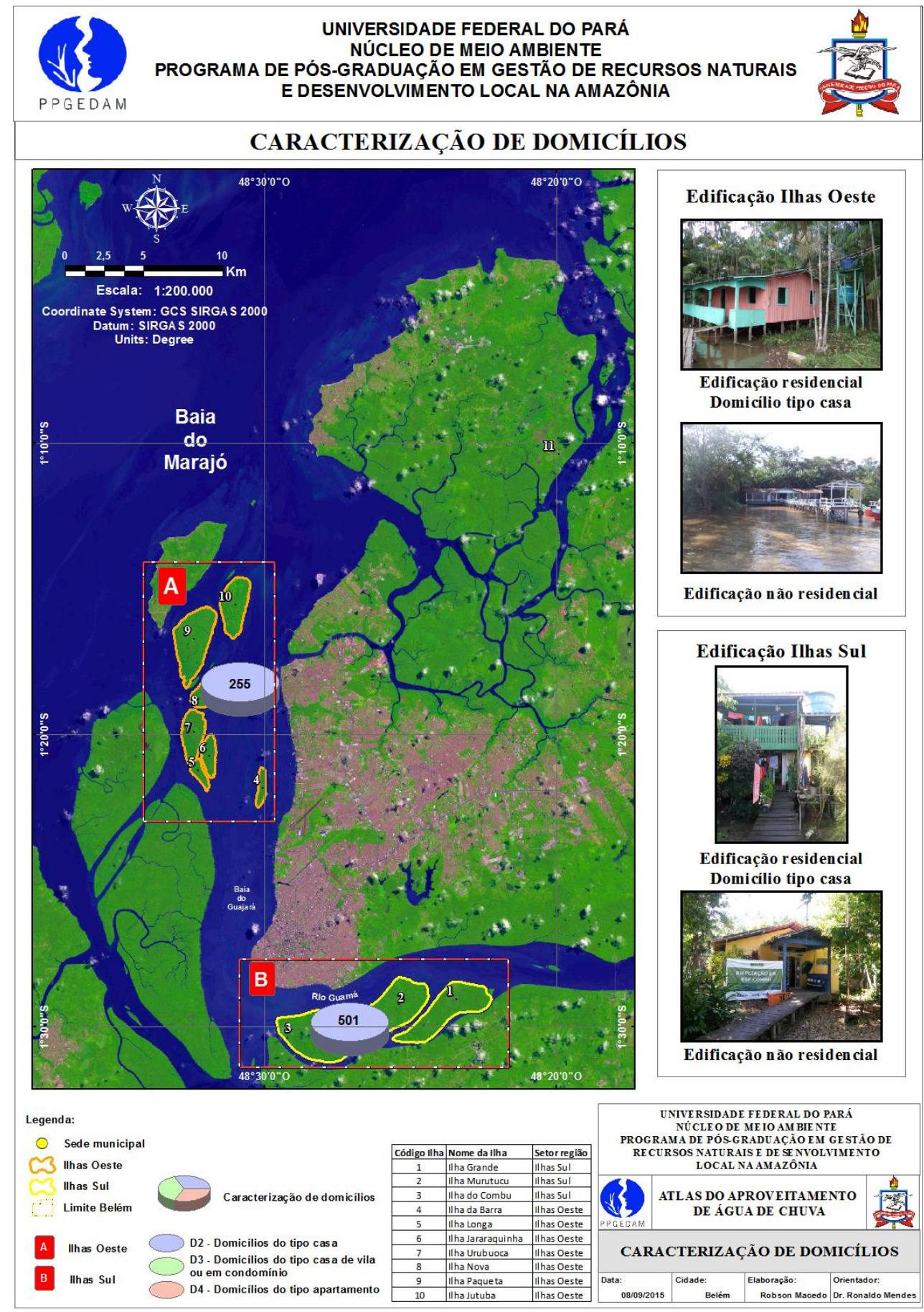

Figura 4. Tipo de domicílios identificados nas ilhas. Fonte: Elaborado pelo autor

Considerando os sistemas de abastecimento de água informados pelo IBGE, nas ilhas localizadas à Oeste, foram identificados 7 moradores com acesso ao sistema de abastecimento de água da Rede Geral e 7 moradores com abastecimento de água de poço ou nascente na propriedade na região das ilhas ao Sul. Esse dado traz à discussão a compreensão do que é o sistema de abastecimento de água da rede geral, quando por meio da pesquisa bibliográfica e etapa de campo não foi identificado nas ilhas 
sistemas de abastecimento de água de rede geral no formato convencional do perímetro urbano como os de rede geridos por concessionárias. Também não foi identificado sistema uso de poços nas ilhas, quando as ilhas são constituídas no geral de área alagáveis.

Como pode ser visto no Tabela 2, em termos percentuais nas ilhas localizadas a Oeste $37,5 \%$ dos moradores fazem uso de sistemas de captação de água de chuva em cisterna, em termos absolutos são 392 moradores. Os 61,8\% restantes, 646 moradores, são abastecidos por outras formas de abastecimento. Nas ilhas localizadas ao Sul, o percentual de moradores com acesso à "outra forma de abastecimento" foi de 99,7\%, ou seja, 1.997 moradores. Vale ressaltar que para as ilhas inseridas nessa pesquisa, pode-se afirmar que a opção: - carro pipa e açude, não fazem parte da realidade local pelas características da região como já mencionado anteriormente.

Para melhor compreensão geográfica dos dados discutidos, a Figura 5 apresenta a distribuição espacial dos dados apresentados. Por meio dos dados apresentados na Tabela 2, é possível concluir que uma das principais alternativas de acesso à água é por meio do abastecimento de água de chuva armazenada em cisterna

\begin{tabular}{|c|c|c|c|c|c|}
\hline $\begin{array}{c}\text { Tipo } \\
\text { Abastecimento de água }\end{array}$ & Ilhas Oeste & $\begin{array}{c}\text { Ilhas } \\
\text { Sul }\end{array}$ & $\begin{array}{c}\text { Ilhas Oeste } \\
(\%)\end{array}$ & $\begin{array}{c}\text { Ilhas Sul } \\
(\%)\end{array}$ & Total Geral \\
\hline $\begin{array}{l}\text { Moradores com abastecimento de } \\
\text { água da rede geral - A1 }\end{array}$ & 7 & 0 & $0,7 \%$ & $0,0 \%$ & 7 \\
\hline $\begin{array}{l}\text { Moradores com abastecimento de } \\
\text { água de poço ou nascente na } \\
\text { propriedade - A2 }\end{array}$ & 0 & 7 & $0,0 \%$ & $0,3 \%$ & 7 \\
\hline $\begin{array}{l}\text { Moradores com abastecimento de } \\
\text { água de chuva armazenada em } \\
\text { cisterna - A3 }\end{array}$ & 392 & 0 & $37,5 \%$ & $0,0 \%$ & 392 \\
\hline $\begin{array}{l}\text { Moradores em domicílios particulares } \\
\text { permanentes com outra forma de } \\
\text { abastecimento de água - A4 }\end{array}$ & 646 & 1.997 & $61,8 \%$ & $99,7 \%$ & 2643 \\
\hline Total de moradores & 1045 & 2.004 & $34 \%$ & $66 \%$ & 3049 \\
\hline
\end{tabular}

Tabela 2. Quantitativo de moradores com acesso e abastecimento de água. Fonte: - Censo 2010 - IBGE

Quanto às outras formas de abastecimento, se percebe uma lacuna nos dados disponibilizados pelo censo, porém a pesquisa documental permitiu o reforço de que o uso de água de chuva nas ilhas é uma opção muito utilizada pela população local. O Plano Municipal de Saneamento Básico de Abastecimento de Água e Esgotamento Sanitário de Belém, do ano de 2014, apresenta uma mudança significativa 
quanto a gestão de águas das ilhas. Se no Plano de 2004 as ilhas não foram inseridas como áreas prioritárias, em 2014 o abastecimento de água nas ilhas é identificado por meio de tecnologias alternativas individuais trazendo como inovações alternativas a captação de água de chuva em áreas que, segundo o Plano Diretor Municipal de 2008, observa como Zona do Ambiente Natural 3 (ZAN 3), caracterizadas como áreas de várzea, com existência de comunidades ribeirinhas e sem formação de núcleos urbanos.

No levantamento de campo foram identificadas outras formas de abastecimento de água como a captação de água do rio, águas fornecidas por barqueiros da região (águas captadas em poços), águas de concessionárias e água "mineral" comprada no perímetro urbano de Belém".

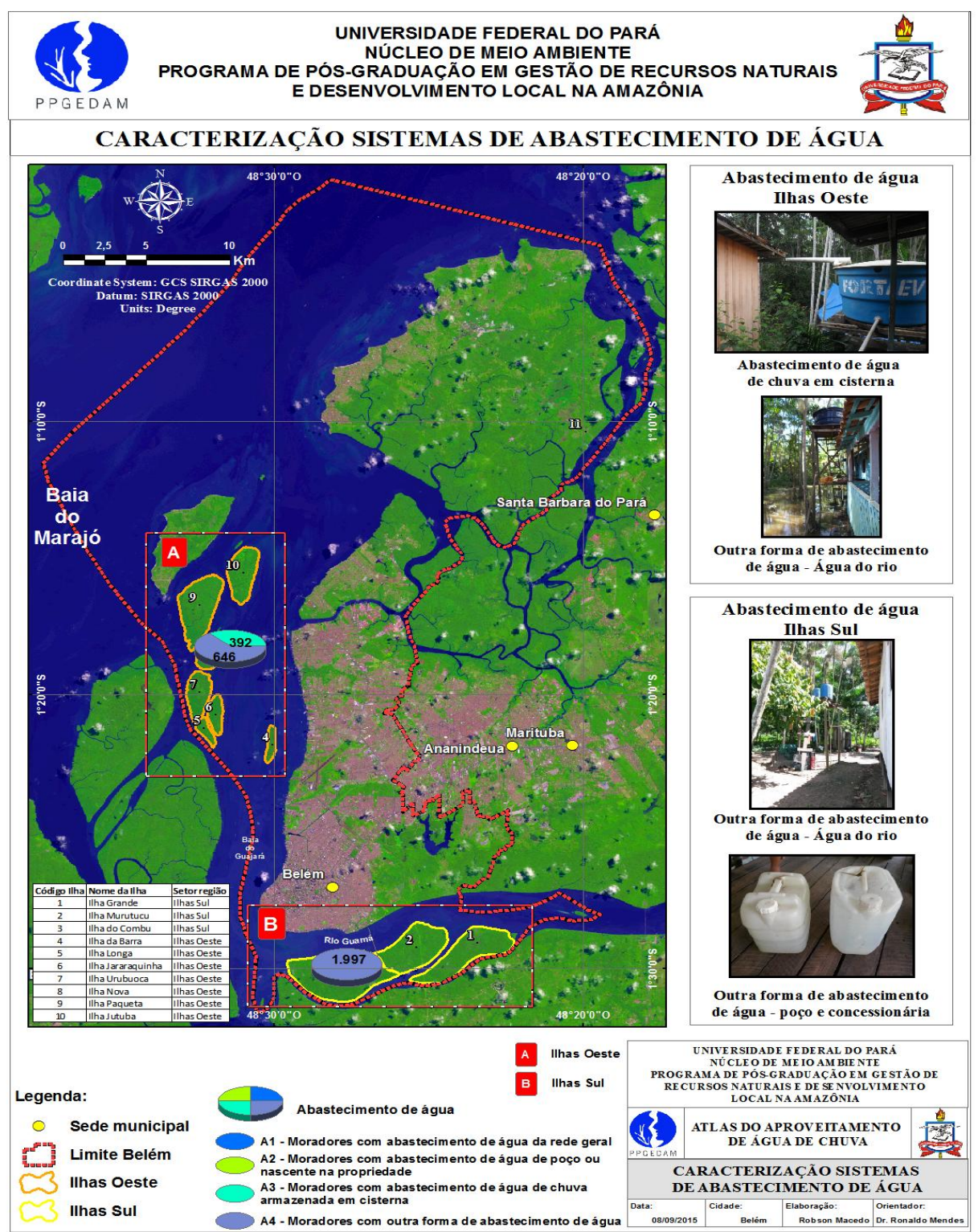

Figura 5. População com acesso ao abastecimento de água. Fonte: Elaborado pelo autor 


\section{Iniciativas de uso de água da chuva no contexto da região insular de Belém}

A construção de um cenário preliminar, por meio do diagnóstico temático, permitiu o entendimento de que a população ribeirinha localizada à Oeste e ao Sul de Belém vivia em situação de quase exclusão social quando não tem acesso a serviços básicos associados à garantia de qualidade de vida. Em se tratando da água consumida nas ilhas, foram identificadas três principais fontes de água para o abastecimento dos moradores da região das ilhas. (Figura 6). Como já tratado por outros pesquisadores, foi confirmado à utilização de água de chuva, águas de poços e águas dos rios da região. Segundo Andrade (2012, pag. 80) "as fontes de abastecimento de água da população das ilhas são diversas, mananciais de água superficial e subterrânea, água transportada de Belém e do Acará".

Porém, aqui serão destacadas as fontes das águas encontradas nos domicílios dos moradores. Segundo Rosa (2010, pag. 2) "A disponibilidade de água em quantidade e qualidade adequadas para os diversos usos, atua como fator determinante no processo de desenvolvimento econômico e social de uma comunidade." Assim, a discussão sobre o uso da água da chuva nas ilhas de Belém não é novidade, porém, aqui se busca relacionar as iniciativas de aproveitamento de água de chuva às outras formas de abastecimento de água, buscando assim uma compreensão mais ampla sobre o uso da água da chuva em uma região rica em recursos hídricos, porém prejudicada pela degradação da qualidade da água disponível.

As ilhas à Oeste são banhadas pelas águas da Baia do Guajará, já ao Sul as ilhas são banhadas pelo rio Guamá e seus afluentes. Em ambas as áreas se observa a ocorrência de variação de maré, onde por meio das entrevistas de campo, se observou que a própria variação da maré influência no uso da água quando a captação de água do rio no geral, segundo os moradores, se dá no momento em que a maré está "alta". 


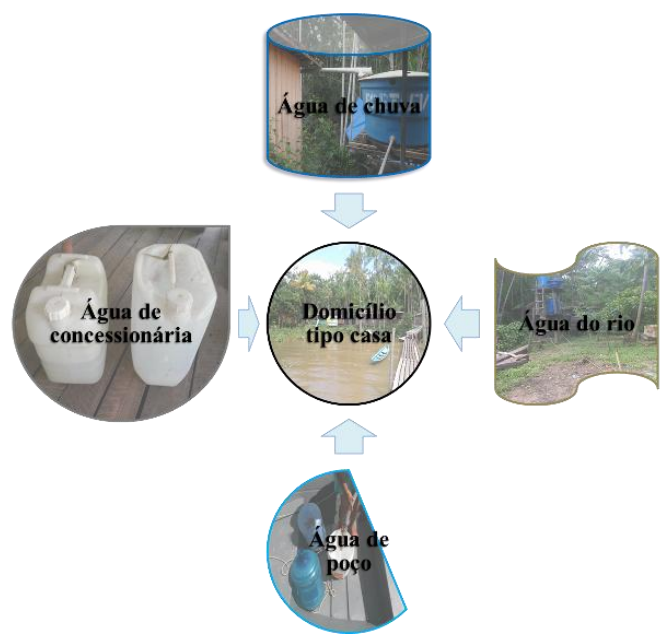

Figura 6. Fontes de abastecimento de água. Fonte: Elaborado pelo autor

Captação de água do rio

A captação de água de rio foi identificada em todas as ilhas inseridas nessa pesquisa, a prática de uso de água do rio para os ribeirinhos não é novidade, porém, há diferentes formas de uso dessa água. Nas ilhas Oeste e Sul a água do rio é no geral utilizada nos afazeres domésticos como lavagem de louças e roupas. Nas ilhas que já tem acesso a rede de energia elétrica observou-se sistema de captação de água do rio com uso de bombeamento para reservatório elevado. Nos outros a coleta é feita de forma manual. (Figura 7)

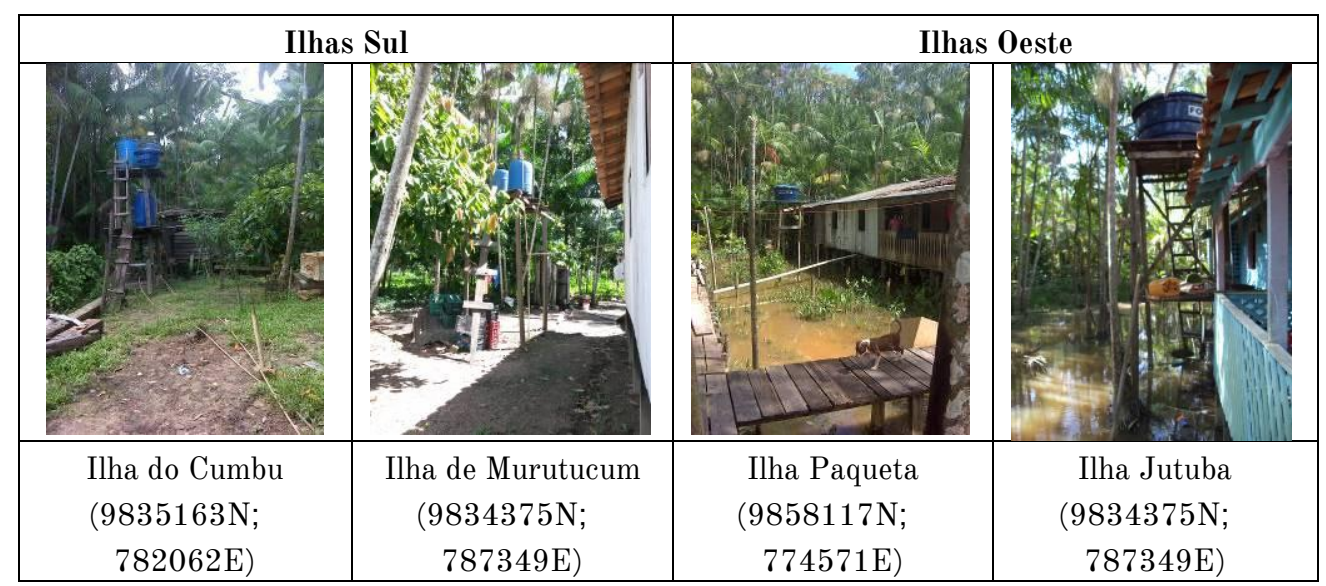

Figura 7. Registro fotográfico e referência geográfica de iniciativas de captação de água do rio.

Fonte: Elaborado pelo autor

Captação de água da chuva

A localização exata das iniciativas de uso da água da chuva nas ilhas de Belém ainda é um desafio, tendo em vista o custo de levantamento dessa informação. Porém, o Atlas aqui apresentado trará mais 
um passo ao processo de identificação e localização espacial dos usuários de água da chuva nas ilhas, considerando aspectos relacionados aos temas Ambiental e Social. Por meio da pesquisa documental se observou que nas ilhas localizadas a Oeste de Belém (Jutuba, Paquetá, Ilha Nova, Ilha Longa, Jararaquinha e Ilha da Barra), em 2010, identificou-se 392 domicílios que faziam uso da água da chuva. Por meio de produtos acadêmicos, foram conhecidas as iniciativas localizadas ao Sul de Belém (Ilha Grande, Murutucu e Combú). Para a compreensão geográfica das iniciativas identificadas, foi elaborado o mapa representado pela Figura 8.
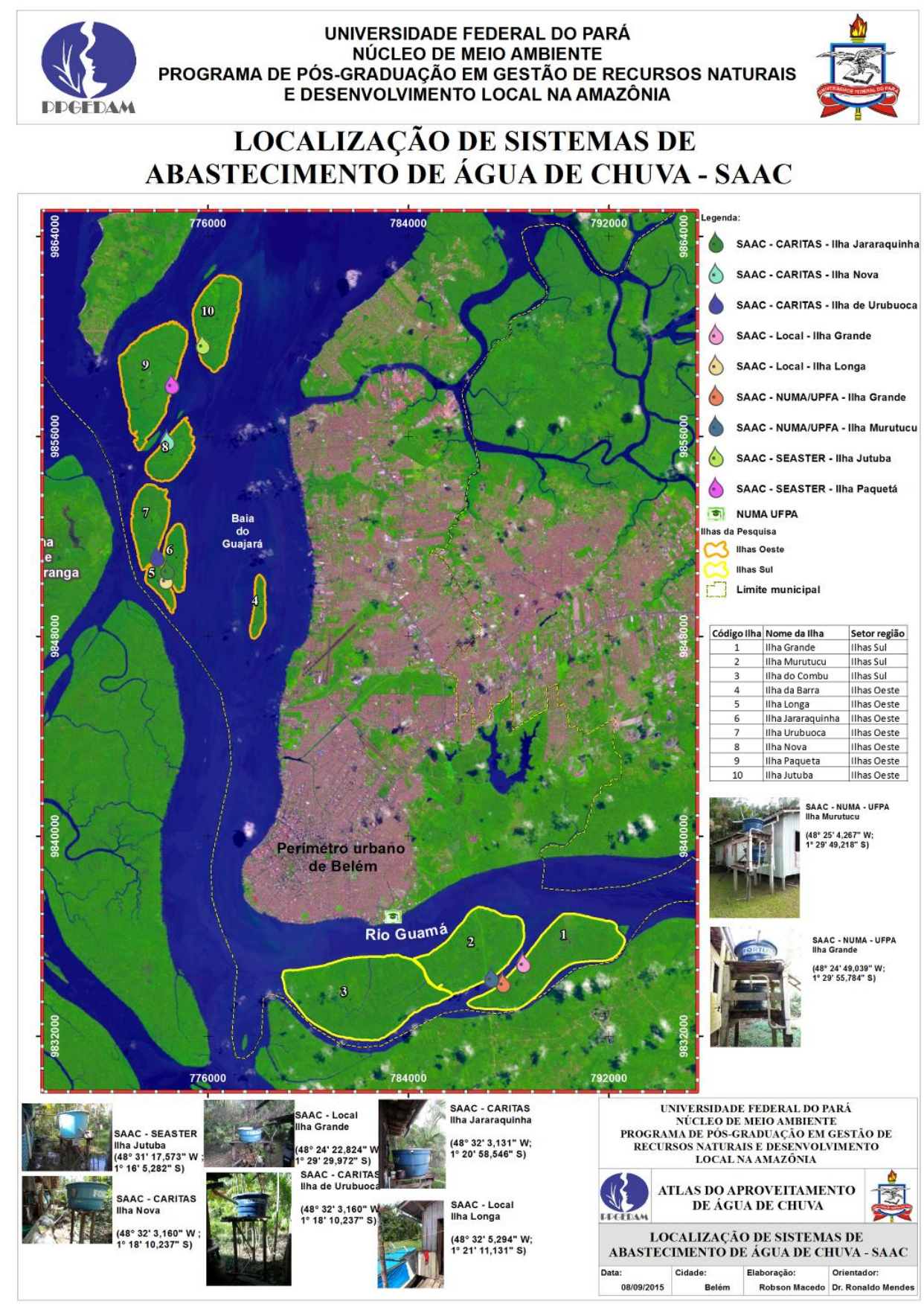

Figura 8. Localização de sistemas de abastecimento de água de chuva. Fonte: Elaborado pelo autor. 
Com auxilio da pesquisa documental e o levantamento de campo foram identificados de 5 (cinco) projetos diferentes de captação de água de chuva - Sistemas de Aproveitamento de Água da Chuva (SAAC) - exemplos de iniciativas locais representam muito bem a realidade encontrada nas ilhas de Belém. Os sistemas encontrados foram descritos segundo suas características técnicas considerando o aporte das tecnologias sociais na formatação dos projetos identificados. Um resumo dos projetos é apresentado na Figura 9.

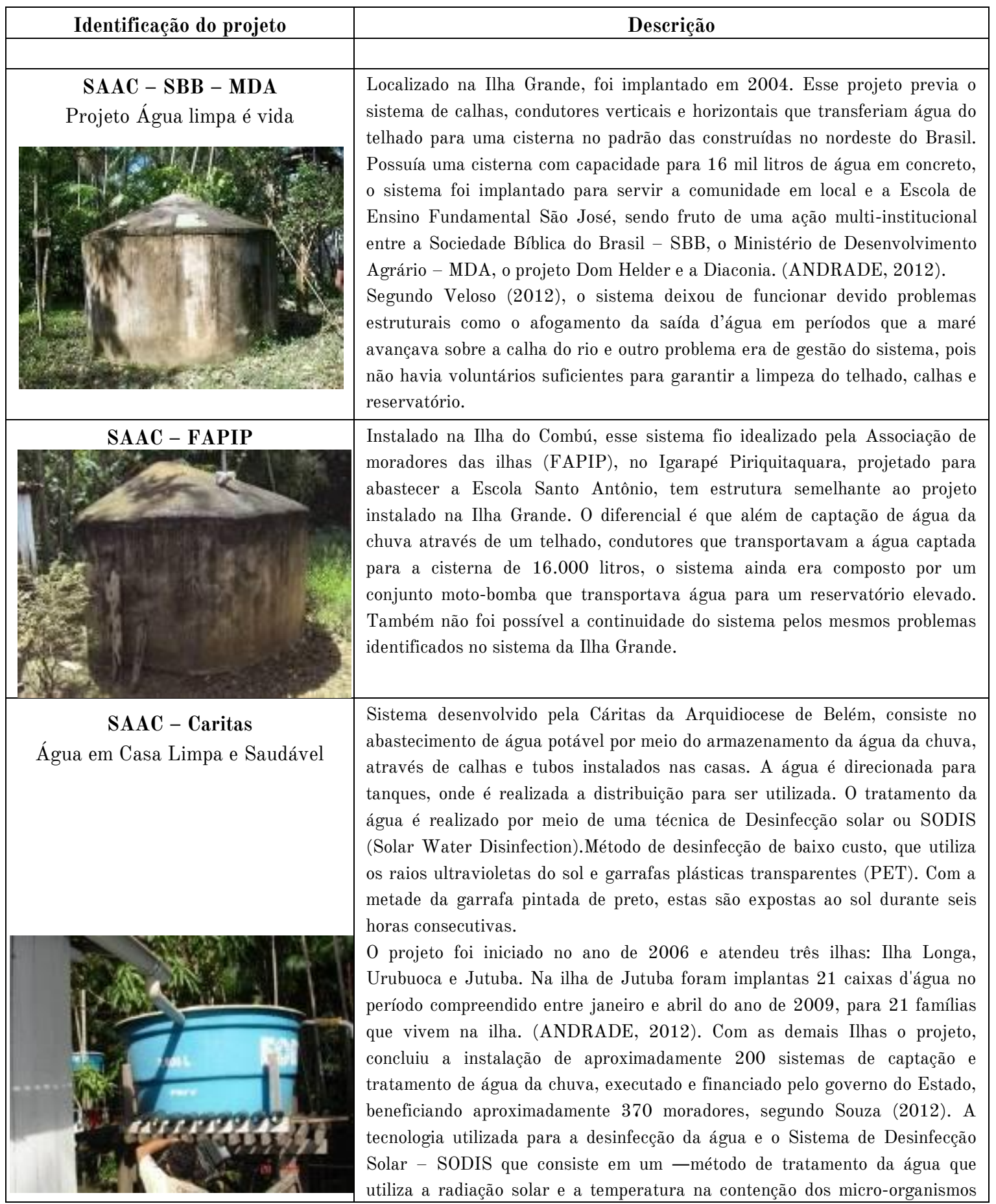




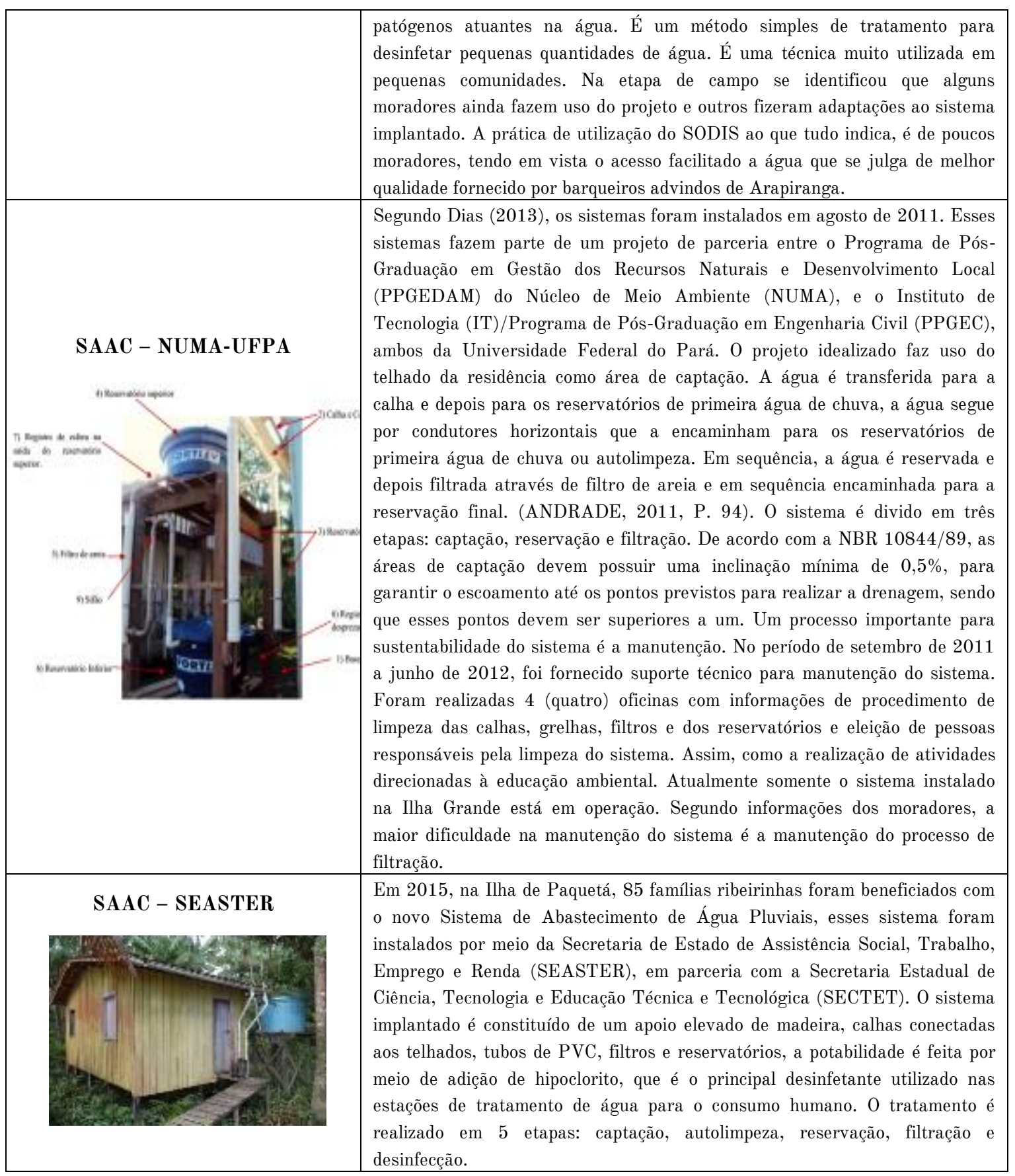

Figura 9. Resumo dos sistemas de aproveitamento de água de chuva (SAAC) identificados nas ilhas. Fonte:

Elaborado pelo autor.

\section{Sistema Domiciliar Integrado de Gestão de Uso de Águas}

Observa-se que a população das ilhas já opera um sistema de gestão das águas, se conscientemente ou não, não temos elementos nessa pesquisa para tal afirmação. A etapa de campo proporcionou o conhecimento da utilização da água disponível de forma integrada dentro de um sistema bem definido. Essas iniciativas de uso alternativo das águas disponíveis mostra uma postura local compatível com os 
objetivos do modelo de gestão integrada estabelecido pela PNGRH, onde as ações predominantes do Sistema de Gestão Estadual buscam a elaboração de mecanismos integrados de controle das necessidades da água e apresentação de proposições sobre estratégias direcionadas de conscientização das comunidades sobre a importância e a necessidade de conservação e manejo integrado dos recursos hídricos.

O primeiro exemplo de uso integrado das águas pode se observar nas ilhas Jutuba e Ilha Grande. Localizada a Oeste de Belém, mais especificamente na ilha Jutuba, em uma mesma residência foi identificado dois sistemas distintos de captação de águas. Um sistema consiste na captação de água do rio, constituído por bomba e reservatório elevado, esse sistema é utilizado com armazenamento de água rio a ser utilizado de forma secundária em casos de falta de água de chuva para lavagem de roupa e louças. Como tratamento, esse sistema recebe apenas a adição de sulfato de alumínio para decantação das partículas em suspensão que dão a coloração barrenta à água captada do rio. Segundo informação dos moradores a água do rio já não é mais uma opção de consumo humano. 0 segundo sistema trata-se de um sistema de captação de água de chuva. Instalado no ano de 2015 , esse sistema é utilizado para realização de atividades domésticas e consumo humano. Basicamente esse sistema é constituído de calhas, reservatório elevado e filtro. Os dois sistemas constituem um instrumento de gestão que auxilia os moradores dessa residência a resolverem problemas da falta de água considerando a variação da maré ou falta chuvas. Na Figura 10 pode ser observado um esquema de sistema integrado encontrado nas ilhas

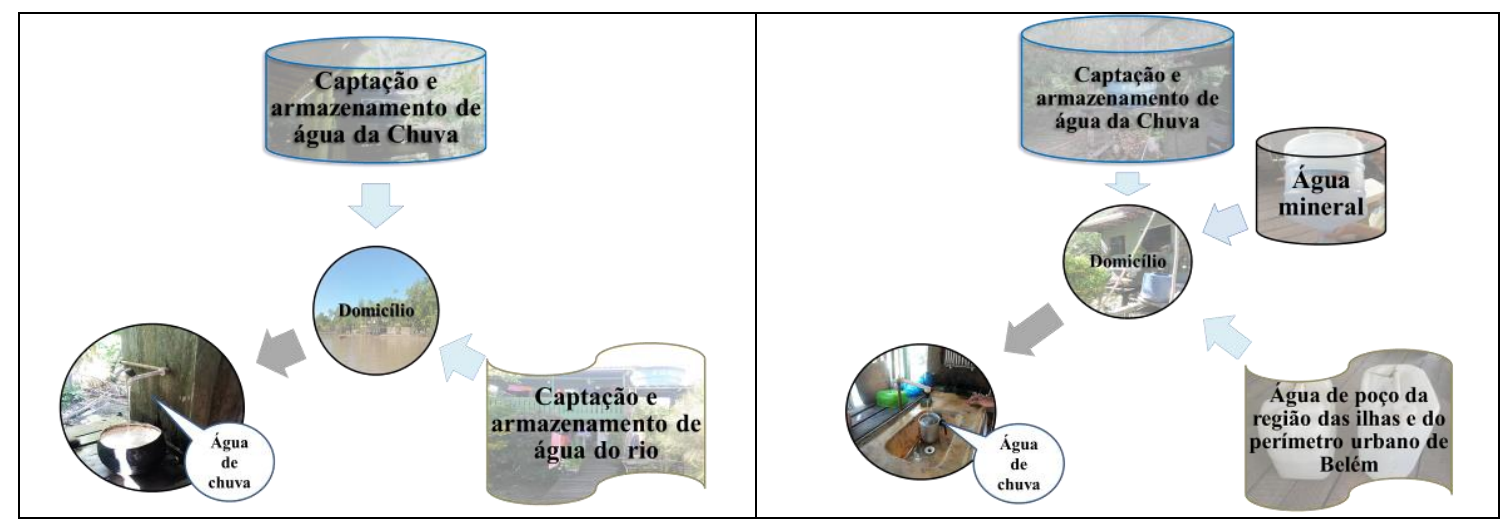

Figura 10. Esquema de sistema integrado de gestão de águas nas ilhas. Fonte: Elaboração do autor.

Um segundo formato de gestão integrada é a combinação de uso de água de poço (adquirida de barqueiro), água de chuva e água comprada no perímetro urbano de Belém. Um exemplo identificado é 
o da ilha Grande, preocupados com a qualidade da água consumida, os moradores dessa residência adotam a captação de água de chuva por um sistema simples de captação pelo telhado, calha e reservatório improvisado. Para esse caso, a água captada tem saída na cozinha e é utilizada somente para afazeres domésticos como lavagem de louças, roupas e da própria casa. Quanto ao uso de água de poço, observou-se que a água recebida é entregue por barqueiros que trazem essa água do município de Acará. Essa água, segundo os moradores, não é consumida por orientação médica, um dos moradores entrevistado informou que já teve problemas de saúde relacionados a água consumida.

Quanto a água adquirida no perímetro urbano de Belém, foram observados dois exemplos, água captada em torneiras localizadas em portos, como da Praça Princesa Izabel e Porto da Palha, e água comprada em comércios próximos aos portos. 0 reconhecimento das ilhas inseridas na área de pesquisa levou a compreensão de que uso mais expressivo para consumo humano é o uso de água de poço, fornecido por barqueiros que levam a água até os ribeirinhos ou eles mesmos saem em busca dessa água na área onde se encontram os poços (município de Acará, Barcarena e Ilha de Cotijuba).

Essa pesquisa identificou duas fontes mais utilizadas para o fornecimento de água de poço para as ilhas. À Oeste de Belém, a fonte mais utilizada é de um poço localizado na ilha de Arapiranga. Segundo os moradores das Ilhas Jararaquinha e Paquetá, a água proveniente da Ilha de Arapiranga é fornecida por barqueiros que tem o custo de coleta e transporte dessa água sob a responsabilidade da prefeitura de Barcarena. Segundo esses moradores essa água é fornecida diariamente tendo o morador da ilha a responsabilidade somente de ter seu próprio recipiente de armazenamento de água, como poder ser observado na Figura 11.

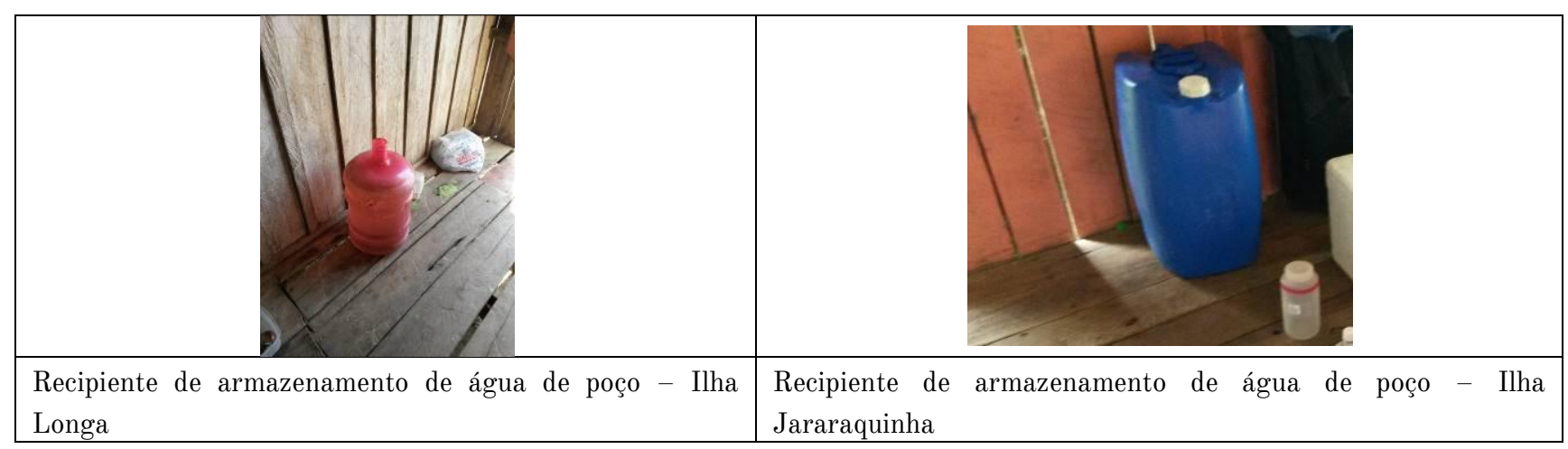

Figura 11. Recipientes de armazenamento de água de poço Ilhas Oeste. Fonte: Elaboração do autor. 
Quanto as Ilhas ao Sul, a água de poço é de origem da comunidade Santa Maria de Boa Vista, localizada no município de Acará. Essa transportada por barqueiro, onde o custo da água no geral é de $\mathrm{R} \$ 3,50$ por 20 litros. Porém ao acompanhar uma compra de água feita no local de instalação do poço, verificou-se que a volume de água recebido não foi o informado como corresponde ao valor pago. 0 fornecimento dessa água de poço não se trata necessariamente de relação estritamente comercial, mas pode haver também uma relação de ajuda entre os ribeirinhos, o que poderá ser levantado em pesquisas outras (Figura 12).

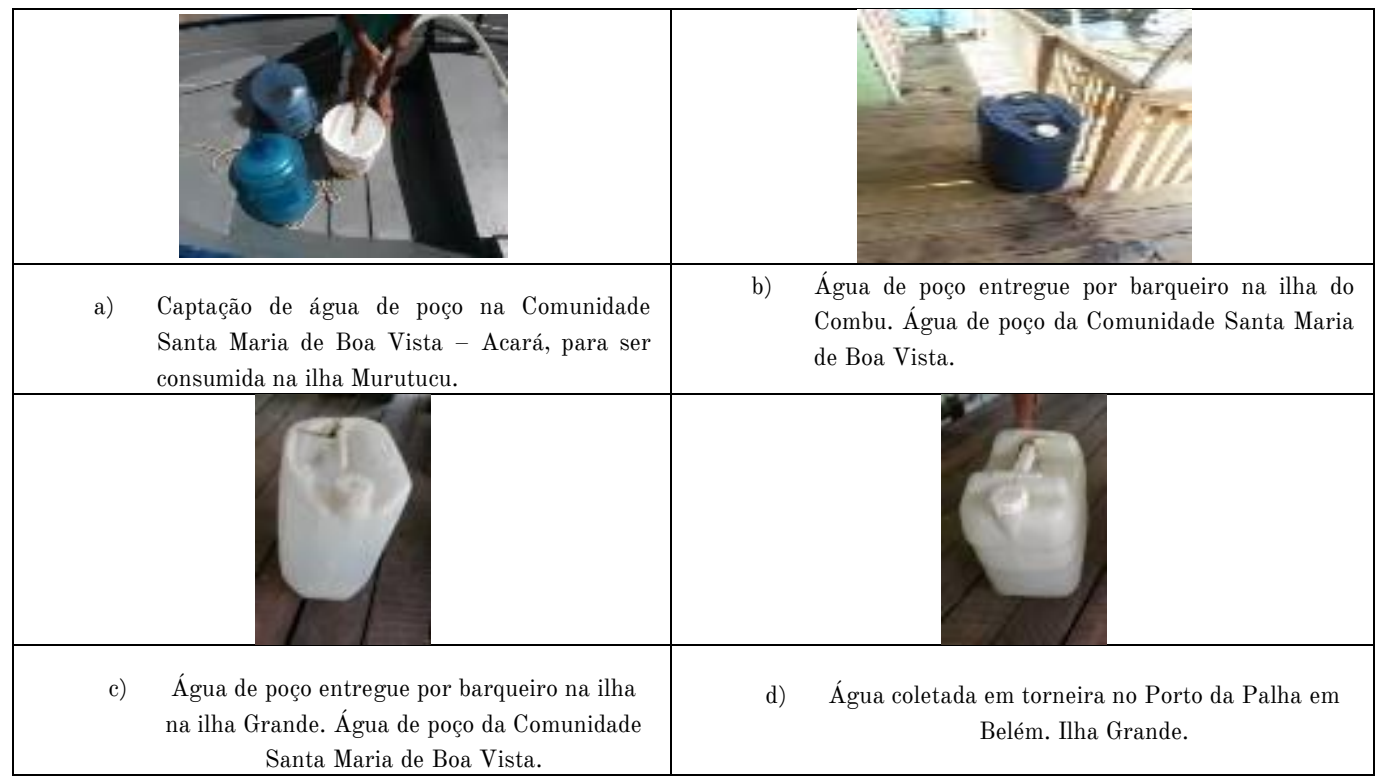

Figura 12. Uso de água de poço nas Ilhas Sul.

\section{Qualidade da água consumida nas ilhas}

Foram coletadas 11 amostras de água que seriam consumidas pelos ribeirinhos (Figura 13). As coletas nas Ilhas Oeste foram realizadas entre os dias 05 e 12/05/2016 e no período de 08 a 09/06/2016 foram realizadas as coletas nas Ilhas ao Sul. A oeste foram realizadas 6 amostragens, as duas primeiras (P1 Ilha Jutuba e P2 Ilha Paquetá), são amostras de um sistema de captação de água de chuva do governo estadual implantado Secretaria de Estado e Assistência Social, Trabalho, Emprego e Renda (SEASTER), em parceria com a Secretaria Estadual de Ciência, Tecnologia e Educação Técnica e Tecnológica (SECTET). As amostras coletadas nos pontos P3 (Ilha Nova) e P4 (Ilha Urubuoca) são de água de chuva de projetos da Cáritas da Arquidiocese de Belém. Quanto à amostra 
do P5 (Ilha Longa) trata-se de água de chuva coletada de uma calha improvisada, água que seria consumida pela falta de outra fonte. No P6 (Ilha Jararaquinha) a amostra coleta trata-se de água de poço fornecida por barqueiro.

\begin{tabular}{|c|c|c|c|c|c|}
\hline Área & $\begin{array}{c}\text { Pontos } \\
\text { de coleta }\end{array}$ & Ilha & Fonte & Latitude & Longitude \\
\hline \multirow{6}{*}{ Ilhas Oeste } & $\mathrm{P} 1$ & Ilha Jutuba & \multirow{5}{*}{ Água de chuva } & $1^{\circ} 16^{\prime} 5,282^{\prime \prime} \mathrm{S}$ & $48^{\circ} 31^{\prime} 17,573^{\prime \prime} 0$ \\
\hline & P2 & Ilha Paquetá & & $1^{\circ} 16^{\prime} 56,906^{\prime \prime} \mathrm{S}$ & $48^{\circ} 31^{\prime} 57,511^{\prime \prime} 0$ \\
\hline & P3 & Ilha Nova & & $1^{\circ} 18^{\prime} 10,237^{\prime \prime} \mathrm{S}$ & $48^{\circ} 32^{\prime} 3,160^{\prime \prime} \mathrm{O}$ \\
\hline & $\mathrm{P} 4$ & Ilha de Urubuoca & & $1^{\circ} 20^{\prime} 41,489^{\prime \prime} \mathrm{S}$ & $48^{\circ} 32^{\prime} 16,469^{\prime \prime} 0$ \\
\hline & P5 & Ilha Longa & & $1^{\circ} 21^{\prime} 11,131^{\prime \prime} \mathrm{S}$ & $48^{\circ} 32^{\prime} 5,294^{\prime \prime} 0$ \\
\hline & $\mathrm{P} 6$ & Ilha Jararaquinha & Água de poço & $1^{\circ} 20^{\prime} 58,546^{\prime \prime} \mathrm{S}$ & $48^{\circ} 32^{\prime} 3,131^{\prime \prime} \mathrm{O}$ \\
\hline \multirow{4}{*}{ Ilhas Sul } & $\mathrm{P} 7$ & Ilha Grande & Água de chuva & $1^{\circ} 29^{\prime} 55,784^{\prime \prime} \mathrm{S}$ & $48^{\circ} 24^{\prime} 49,039^{\prime \prime} \mathrm{O}$ \\
\hline & P8 & Ilha Murutucu & \multirow{2}{*}{ Água de poço } & $1^{\circ} 29^{\prime} 49,218^{\prime \prime} \mathrm{S}$ & $48^{\circ} 25^{\prime} 4,267^{\prime \prime} 0$ \\
\hline & P9 & Ilha do Combu & & $1^{\circ} 29^{\prime} 23,464^{\prime \prime} \mathrm{S}$ & $48^{\circ} 27^{\prime} 54,796^{\prime \prime} \mathrm{O}$ \\
\hline & P10 & Ilha Grande & $\begin{array}{l}\text { Água mineral } \\
\text { e água de poço }\end{array}$ & $1^{\circ} 29^{\prime} 29,972 " \mathrm{~S}$ & $48^{\circ} 24^{\prime} 22,824^{\prime \prime} \mathrm{O}$ \\
\hline
\end{tabular}

Quadro 1. Uso de água de poço nas Ilhas Sul.

Nas ilhas localizadas na área Sul foram coletadas 5 amostras. Os pontos P7 e P10 estão localizados na ilha Grande, no P7 a amostra coleta é de um sistema projetado pelo GPAC da Universidade Federal do Pará e no P10 foram coletadas 1 amostra de água de poço fornecida por barqueiro que vende água na região e 1 amostra de água mineral comprada na região portuária de Belém. Quanto aos pontos P8 (Ilha Murutucu) e P9 (Ilha Combu), as amostras são de água de poço comprada de barqueiros. No Quadro 1 são apresentados os pontos de coleta de água realizados e suas respectivas coordenadas geográficas.

Os parâmetros analisados foram determinados em consonância com a portaria do Ministério da Saúde (MS) $n^{\circ} 2914$ de 12/12/2011 e a análise laboratorial realizada pelo Instituto Evandro Chagas (IEC), por meio do setor de meio ambiente. Os parâmetros analisados são apresentados na Tabela 3 . Na portaria 2914/2011, valores de referência de pH para o padrão de potabilidade está entre 6 e 9 . No entanto, nos pontos P4 (água de chuva), P6 (água de poço), P9 e P10 (água de poço e água mineral) este parâmetro atingiu valores de $\mathrm{pH}$ ácido de 4,53 à 5,7 o que representa um risco a longo prazo à população que consome essas águas pois a ocorrência de pH ácido pode ocasionar em problemas gástricos, como gastrites, úlceras e câncer de estômago. 
Os valores do parâmetro Oxigênio Dissolvido (OD) apresentaram-se de acordo com os padrões de referência para classe 2 da Resolução ํํ3 357/2005 (acima de $5 \mathrm{mg} / \mathrm{L}$ ), ou seja, água que pode ser destinada ao consumo humano, após tratamento convencional. Porém nos pontos P4 (4,50), P5 $(4,30), \mathrm{P} 6(4,35), \mathrm{P} 11(4,63)$ e $\mathrm{P} 12(4,91)$ os valores medidos estão no intervalo de 4,50 à 4,91 ppm e não se enquadrando como águas apropriadas ao consumo sem o devido tratamento, águas com baixos teores de oxigênio dissolvido indicam que essa água recebeu quantidade significativa matéria orgânica.

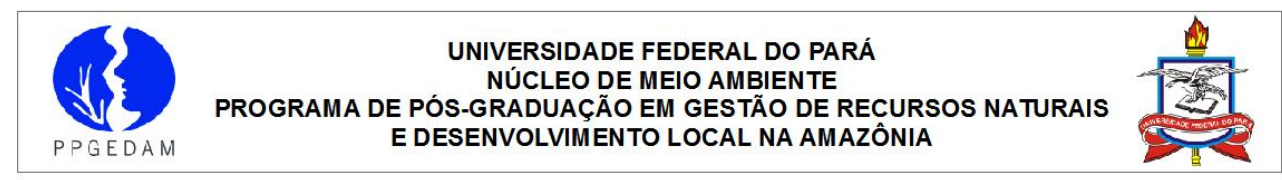

\section{LOCALIZAÇÃO DOS PONTOS DE COLETA DE ÁGUA}

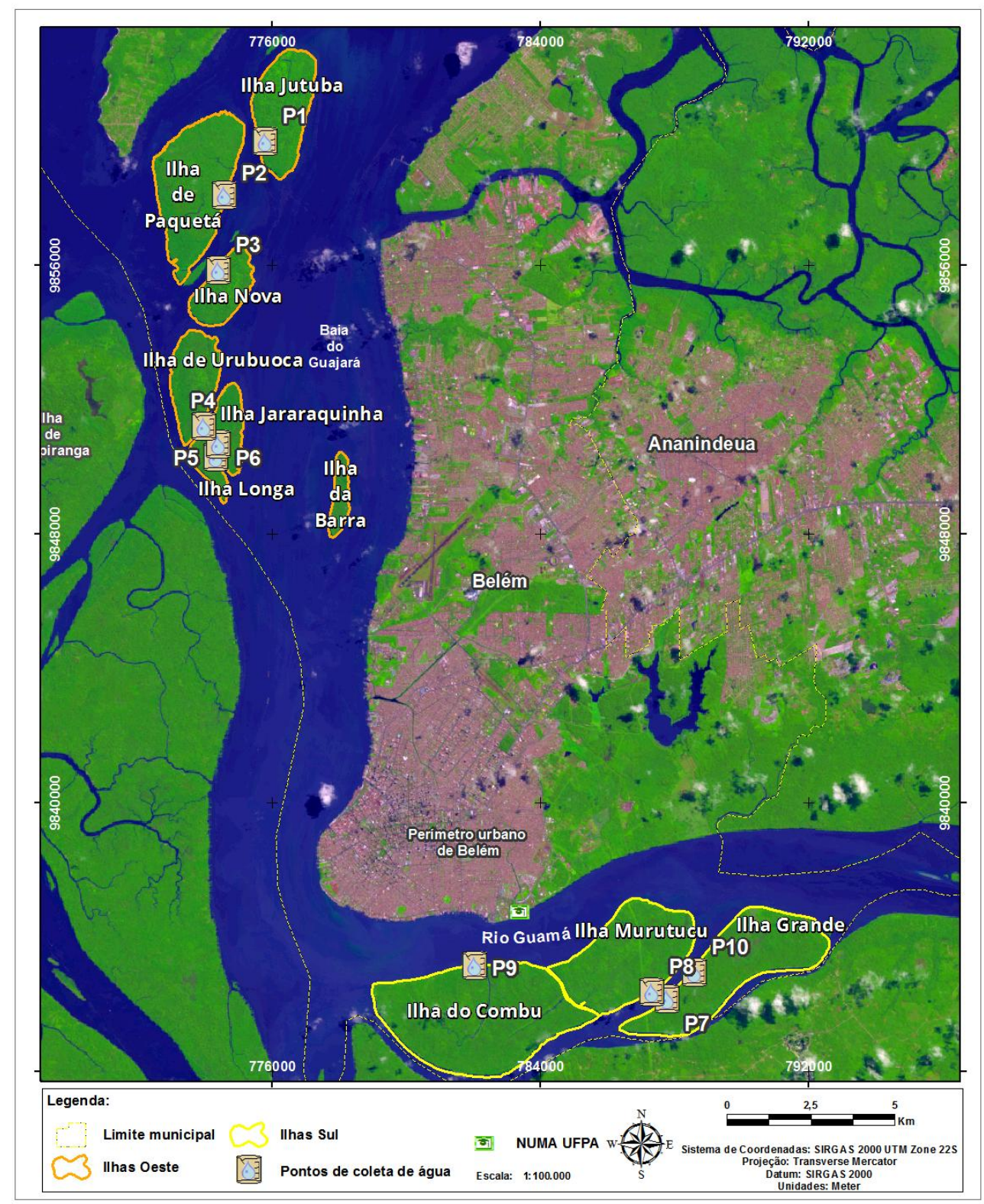

Figura 12. Localização dos pontos de coleta de água. Fonte: Elaboração do autor. 
A Condutividade Elétrica mede a facilidade de uma água em conduzir a corrente elétrica e está diretamente relacionada com o teor de sais dissolvidos sob a forma de íons. Os resultados das análises indicaram que no ponto $\mathrm{P} 6$ o valor da condutividade foi de $39 \mu \mathrm{S} / \mathrm{cm}$, nos demais pontos, este parâmetro apresentou valores variando entre 9,0 e $21 \mu \mathrm{S} / \mathrm{cm}$. Os valores de Sólidos Totais Dissolvidos (TDS) observados variaram entre 5 e $19 \mathrm{mg} / \mathrm{L}$, para águas classe 2, não podem ultrapassar o limite de $500 \mathrm{mg} / \mathrm{L}$ (CONAMA 357). Todas as amostras analisadas mostraram o comportamento de acordo com o padrão de qualidade legislado. Alguns dos valores para o parâmetro Sólidos Totais Suspensos (STS) ficaram abaixo do limite de detecção do aparelho enquanto que as outras medições ficaram no intervalo entre 1 e 4,0 mg/L. Segundo a classificação mundial das águas doce é aquele que apresenta teor de sólidos totais dissolvidos (STD) inferior a $1.000 \mathrm{mg} / \mathrm{L}$, sendo esta essencial ao abastecimento do consumo humano. Por meio da análise realizada todos os valores quantificados estão abaixo do valor de referência caracterizando assim as águas analisadas como água doce.

Os valores do parâmetro Fluoreto (padrão da classe 2 é de 1,4 mg/L) estiveram abaixo dos valores de referência e dentro dos padrões de qualidade da legislação vigente. Os Cloretos são advindos da dissolução de sais e é utilizado como parâmetro legislado para águas classe 2, com padrão de qualidade de $250 \mathrm{mg} / \mathrm{L}$. A presença de cloro em águas superficiais pode estar relacionada com intrusão marinha, dissolução de minerais ou por diferentes atividades antropogênicas, tais como: presença de esgoto doméstico, efluentes industriais, que não é caso das amostras de água de chuva. Em todas as amostras analisadas de cloreto, se verificou valores bem abaixo dos padrões de qualidade para águas classe II da resolução CONAMA 357/2005. Os valores de Nitrato foram detectados nas amostras localizadas nas ilhas ao sul de Belém e apresentaram valores entre 0,86 e 2,67, assim, ficaram abaixo do valor padrão de potabilidade para substâncias químicas que representam risco à saúde que é de $10 \mathrm{mg} / \mathrm{L}$ para o nitrato. (Portaria 2914/211). O Nitrato é facilmente dissolvido nas águas subterrâneas e é muito móvel em fluxos superficiais, difundindo-se muito rapidamente. Os nitratos ocorrem naturalmente nas águas por dissolução de rochas ou, principalmente, por oxidação bacteriana de matéria orgânica. 
Os valores de Nitrito e Nitrogênio Amoniacal ficaram abaixo do limite de detecção do aparelho. As maiores concentrações de nitrato decorrem da utilização de fertilizantes e do lançamento de esgotos orgânicos. Nitrogênio merece especial atenção nas análises químicas das amostras dos esgotos porque sendo um nutriente indispensável para o crescimento dos microrganismos responsáveis pela depuração biológica, seus compostos favorecem o desenvolvimento de algas e plantas aquáticas que podem comprometer a qualidade dos efluentes, caso sua presença seja excessiva, favorecendo o aparecimento da eutrofização nos corpos receptores.

Os valores observados para o Sulfato situaram-se bem abaixo do valor preconizado para a classe 2 da resolução CONAMA 357/05 (250 mg/L). Os valores analisados de Cálcio ficaram, no geral, abaixo de $1,0 \mathrm{mg} / \mathrm{L}$, somente no ponto P10 (água de chuva) este valor chegou a 7,92mg/L para uma amostra de água de chuva. Vale ressaltar que em muitas situações de tratamento de água, ocorre a necessidade de se alterar o valor do $\mathrm{pH}$ das águas de forma a atender a determinadas exigências, assim para a elevação de pH, os compostos mais utilizados são a soda cáustica (hidróxido de sódio), a cal hidratada (hidróxido de cálcio) e a barrilha (carbonato e bicarbonato de sódio). Os valores do parâmetro Magnésio variaram entre 0,05 e $0,64 \mathrm{mg} / \mathrm{L}$, acima do limite de detecção do aparelho. Quanto à Dureza Total os valores medidos não excedem os valores máximos permitidos para o padrão organoléptico de potabilidade estabelecido na portaria 2914/2011.

Em todas as amostras coletadas foi identificada a presença coliforme totais, nesse caso, as amostras coletadas não atendem ao padrão microbiológico para potabilidade da água determinada na Portaria MS № 2914 DE 12/12/2011. Com relação ao parâmetro Escherichia coli, segundo a Portaria referida, a detecção desse parâmetro nas amostras é um indicador de contaminação fecal, o que tornaria as amostras impróprias para o consumo humano, com exceção dos pontos P9 (água de poço) e P10 (água de chuva).

\begin{tabular}{cccccccccccccc}
\hline Parâmetro & Unid. & P1 & P2 & P3 & P4 & P5 & P6 & P7 & P8 & P9 & $\begin{array}{c}\text { P10 - } \\
\text { Água } \\
\text { mineral }\end{array}$ & $\begin{array}{c}\text { P10 }- \\
\text { Áua de } \\
\text { ehuva }\end{array}$ \\
\hline $\begin{array}{c}\text { Temperatura } \\
\begin{array}{c}\text { Oxigênio } \\
\text { Dissolvido - 0D }\end{array}\end{array}$ & ${ }^{\circ} \mathrm{C}$ & 26,66 & 25,53 & 26,43 & 27,7 & 28,8 & 27,8 & 19,34 & 19,91 & 22,77 & 21,13 & 20,55 \\
\hline
\end{tabular}




\begin{tabular}{|c|c|c|c|c|c|c|c|c|c|c|c|c|}
\hline Condutividade & $\mu \mathrm{S} / \mathrm{cm}$ & 11 & 21 & 10 & 9 & 18 & 39 & 22 & 20 & 18 & 21 & 20 \\
\hline \multicolumn{13}{|l|}{ Sólidos Totais } \\
\hline $\begin{array}{l}\text { Dissolvidos - } \\
\text { TDS }\end{array}$ & $\mathrm{mg} / \mathrm{L}$ & 5 & 11 & 5 & 5 & 9 & 19 & 11 & 10 & 9 & 10 & 10 \\
\hline \multicolumn{13}{|l|}{ Potencial } \\
\hline $\begin{array}{c}\text { Hidrogeniônico - } \\
\text { pH }\end{array}$ & - & 6,27 & 6,13 & 6,31 & 4,53 & 6,66 & 4,42 & 6,69 & 4,95 & 5,41 & 5,74 & 7,3 \\
\hline Cor Aparente & $\mathrm{mg} / \mathrm{L}$ & 9 & 20,5 & 8 & 14,5 & 20,5 & 20 & 6 & 5 & 3 & 4 & 27 \\
\hline $\begin{array}{c}\text { Sólidos Totais } \\
\text { em Suspensão - } \\
\text { STS }\end{array}$ & $\mathrm{mg} / \mathrm{L}$ & 1 & 1 & $<\mathrm{LD}$ & 2 & 3 & 2,5 & 1 & $<\mathrm{LD}$ & $<\mathrm{LD}$ & 3 & 4 \\
\hline Turbidez & $\mathrm{mg} / \mathrm{L}$ & 1 & 2 & $<\mathrm{LD}$ & 2 & 3 & 2,5 & $<\mathrm{LD}$ & $<\mathrm{LD}$ & $<\mathrm{LD}$ & $<\mathrm{LD}$ & 3 \\
\hline Alcalinidade & $\mathrm{mg} / \mathrm{L}$ & 30 & 50 & 50 & 10 & 10 & 10 & 50 & 20 & 20 & 40 & 130 \\
\hline Fluoreto & $\mathrm{mg} / \mathrm{L}$ & $<\mathrm{LD}$ & 0,006 & 0,006 & 0,025 & 0,009 & $<\mathrm{LD}$ & $<\mathrm{LD}$ & $<\mathrm{LD}$ & $<\mathrm{LD}$ & 0,19 & 0,28 \\
\hline Cloreto & $\mathrm{mg} / \mathrm{L}$ & 0,33 & 0,72 & 0,73 & 0,39 & 0,32 & 0,81 & 0,23 & 0,61 & 0,62 & 1,04 & 0,49 \\
\hline Nitrito & $\mathrm{mg} / \mathrm{L}$ & $<\mathrm{LD}$ & $<\mathrm{LD}$ & $<\mathrm{LD}$ & $<\mathrm{LD}$ & $<\mathrm{LD}$ & $<\mathrm{LD}$ & $<\mathrm{LD}$ & $<\mathrm{LD}$ & $<\mathrm{LD}$ & $<\mathrm{LD}$ & $<\mathrm{LD}$ \\
\hline Nitrato & $\mathrm{mg} / \mathrm{L}$ & $<\mathrm{LD}$ & $<\mathrm{LD}$ & $<\mathrm{LD}$ & $<\mathrm{LD}$ & $<\mathrm{LD}$ & $<\mathrm{LD}$ & 2,67 & 1,01 & 0,86 & 2,63 & 0,55 \\
\hline $\begin{array}{l}\text { Nitrogênio } \\
\text { Amoniacal }\end{array}$ & $\mathrm{mg} / \mathrm{L}$ & $<\mathrm{LD}$ & $<\mathrm{LD}$ & $<\mathrm{LD}$ & $<\mathrm{LD}$ & $<\mathrm{LD}$ & $<\mathrm{LD}$ & $<\mathrm{LD}$ & $<\mathrm{LD}$ & $<\mathrm{LD}$ & $<\mathrm{LD}$ & $<\mathrm{LD}$ \\
\hline Sulfato & $\mathrm{mg} / \mathrm{L}$ & $<\mathrm{LD}$ & $<\mathrm{LD}$ & $<\mathrm{LD}$ & 0,88 & 0,75 & 3,74 & 0,49 & 2,17 & 2,37 & 0,81 & 1,56 \\
\hline Cáleio & $\mathrm{mg} / \mathrm{L}$ & 0,69 & 2,03 & 2,03 & 0,87 & 2,74 & 1,19 & 0,44 & 0,54 & 0,62 & 0,44 & 7,92 \\
\hline Magnésio & $\mathrm{mg} / \mathrm{L}$ & 0,16 & 0,37 & 0,39 & 0,11 & 0,12 & 0,38 & $<\mathrm{LD}$ & 0,1 & 0,1 & 0,11 & 0,25 \\
\hline Dureza Total & $\mathrm{mg} / \mathrm{L}$ & 0,85 & 2,4 & 2,42 & 0,98 & 2,86 & 1,57 & 0,44 & 0,64 & 0,72 & 0,55 & 8,17 \\
\hline $\begin{array}{c}\text { Coliformes totais } \\
\qquad / 100 \mathrm{ml}\end{array}$ & $\mathrm{NMP} / 100 \mathrm{~mL}$ & Presença & Presença & Presença & Presença & Presença & Presença & Presença & Presença & Presença & Presença & Presença \\
\hline $\begin{array}{c}\text { Escherichia coli } \\
/ 100 \mathrm{ml}\end{array}$ & $\mathrm{NMP} / 100 \mathrm{~mL}$ & Presença & Presença & Presença & Presença & Presença & Presença & Presença & Presença & Ausência & Presença & Ausência \\
\hline
\end{tabular}

Tabela 3. Características físicas e químicas da água coletada segundo parâmetros analisados.

\section{REFERÊNCIAS}

O artigo apresentado mostra que a utilização de SIG na gestão de recursos hídricos, vinculado aos instrumentos governamentais de gestão ambiental, incluindo processos relacionados à captação e uso da água de chuva, pode ser uma importante ferramenta de auxílio à gestão por permitir o aprimoramento dos processos de tomada de decisão a partir da representação das informações disponibilizadas na base de dados, apresentada em mapas geográficos temáticos.

Por meio do reconhecimento das iniciativas locais de aproveitamento de água de chuvas constatou-se que a utilização de água de chuva é uma prática recorrente para a população ribeirinha das 9 (nove) ilhas inseridas na pesquisa. No contexto analisado observou-se que a população ribeirinha das ilhas não é assistida por serviços públicos de coleta de lixo, esgotamento sanitário e abastecimento de água. O mapeamento das iniciativas de aproveitamento de água de chuva proporcionou a identificação de 5 (cinco) projetos diferentes de captação de água de chuva, desenvolvidos a partir do uso de tecnologias 
sociais. Os projetos identificados são operacionalizados considerando questões relacionadas ao poder econômico para compra de água dita de melhor qualidade, captação de água do rio e ciclo das chuvas.

Revela-se importante uma gestão integrada, considerando aspectos socioeconômicos e ambientais que promovam a continuidade de estudos de acompanhamento de projetos alternativos de captação e uso da água de chuva, qualidade da água consumida e investimento em novas pesquisas no que se trata de técnicas de tratamento da água de chuva para o consumo humano quando na análise laboratorial das amostras coletadas observou-se que ainda existe uma carência no processo de tratamento da água consumida nas ilhas. Essa pesquisa também permitiu a elaboração de um banco de dados com informações georreferenciadas sobre os tipos de sistemas de captação instalados, qualidade das águas consumidas nas ilhas e informações socioambientais das áreas pesquisadas, disponibilizados em SIGWEB por meio do link: http://qgiscloud.com/RobsonRaposo/ATLAS_Modelo_SIG_WEB

\section{REFERÊNCIAS}

ABRAMOVAY, Ricardo. O capital social dos territórios: repensando o desenvolvimento rural. Economia Aplicada, 2000. n2. V4. pp 379-397

ALMEIDA, Andréia Bevilaqua; SCARAMELLO, Juliana Massensini; SANTOS, Gustavo Henrique dos. Atlas Geográfico Digital: uma proposta de aplicação no ensino fundamental. Revista Cientifica da Escola de Administração do Exercito, n. 2, 2007. Disponível em: $<$ http://www.educadores.diaadia.pr.gov.br/arquivos/File/2010/artigos_teses/GEOGRAFIA/Artigos/artigo_atlas_digital.pdf $>$

AGUIAR, V.T. "Navegar, com mapas, é bem mais preciso!". In: ALMEDA, R.D. Novos rumos da cartografia escolar: currículo, linguagem e tecnologia. São Paulo: Editora Contexto, 2011.

ANDRADE, Cristiane. Aproveitamento de água da chuva para abastecimento em área rural na Amazônia, estudo de caso: Ilha Grande e Murutucu, Belém-Pará. Dissertação (Mestrado) - Universidade Federal do Pará, Instituto de Tecnologia, Programa de Pós-Graduação em Engenharia Civil, Belém, 2012.

ATLAS, DO DESENVOLVIMENTO HUMANO NO BRASIL. Disponível em: http://www. atlasbrasil. org. br/2013/pt/home. Acesso em, v. 15, p. 12, 2015.

BASTOS, Therezinha. Aspectos climáticos de Belém nos últimos cem anos. Belém: Embrapa Amazônia Oriental, 2002.

BELÉM. Lei nº 8.665, de 30 de julho de 2008, Plano Diretor do município de Belém. Disponível em: <http://www.belem.pa.gov.br/planodiretor/Plano_diretor_atual/Lei_N8655-08_plano_diretor.pdf> Acesso em $01 / 12 / 2017$.

BRASIL, Constituição Federal de 1988. Disponível: http://www.planalto.gov.br/ccivil_03/constituicao/constituicao.htm. 
BRASIL, A LEI № 9.433, DE 8 DE JANEIRO DE 1997, Política Nacional de Recursos Hídricos. Disponível em: Acessado em http://www.planalto.gov.br/ccivil_03/leis/L9433.htm.

CASANOVA, Marco Antonio et al. Banco de dados geográficos. Curitiba: MundoGEO, 2005.

CÂMARA, Gilberto. Anatomia de sistemas de informação geográfica. UNICAMP-Instituto e Computação, 1996.

CÂMARA, Gilberto. QUEIROZ, Gilberto. Arquitetura de Sistemas de Informação Geográficos. Geoprocessamento: Teoria e Aplicações. INPE - Instituto Nacional de Pesquisas Espaciais, 2001. Disponível em www.dpi.inpe.br/gilberto/livro/introd/. Acesso em Dez. 2015.

CONAMA, Resolução. 357/2005. Dispõe sobre a classificação dos corpos de água e diretrizes ambientais para o seu enquadramento, bem como estabelece as condições e padrões de lançamento de efluentes, e dá outras providências, 2005.

COSTA, Jamer. Desenvolvimento de um sistema de alerta de enchente aplicado aos planos de defesa civil em áreas de risco no estado do Pará utilizando Sistema de Informações Geográficas (SIG), caso: cidade de Marabá. Dissertação (Mestrado) Universidade Federal do Pará, Instituto de Tecnologia, Programa de Pós-Graduação em Engenharia Civil, Belém, 2012.

CHAMPAGNE, Patrick. A ruptura com as pré-construções espontâneas ou eruditas. Patrick Champagne e Outros, Iniciação à Prática Sociológica, Petrópolis, Editorial Vozes, p. 171-227, 1998.

DAS, Anup Kumar. Environmental justice atlas (EJAtlas. org): India reaches the top while mapping the ecological conflicts and environmental injustices. 2015.

DE BELÉM, ANUÁRIO Estatístico do Município. Belém. Secretaria Municipal de Coordenação Geral do Planejamento e Gestão, 2007.

DALLABRIDA, W. R. Governança Territorial: a densidade institucional e o capital social no processo de gestão do desenvolvimento territorial. Porto Alegre: Mimeo, 2007.

FILIZOLA, Naziano; GUYOT, Jean Loup. Fluxo de sedimentos em suspensão nos rios da Amazônia. Revista Brasileira de Geociências, v. 41, n. 4, p. 566-576, 2011.

DAVIS Clodoveu, CÂMARA Gilberto. Introdução à Ciência da Geoinformação. INPE, São José dos Campos. 2001.

DIAS, Adriana. A sustentabilidade de tecnologias sociais de abastecimento de água de chuva: 0 Caso de Comunidades Insulares de Belém-PA. 2013. UFPA. Dissertação de Mestrado Belém-PA.

FERREIRA, F. P. B; NASCIMENTO, T. V. Influência dos tipos de telhados na qualidade da água do sistema de abastecimento de água pluvial localizados na região insular de Belém. 2010. Trabalho Acadêmico de Conclusão. (Curso de Tecnologia em Saneamento Ambiental). Instituto Federal de Educação, Ciência e Tecnologia do Pará - IFPA. Belém, 2010.

FLORES, RAFAEL; MENDES, RONALDO; DE OLIVEIRA, DÊNIO; Da Costa, Tony Carlos; VELOSO, NIRCELE . Potencial de captação de água de chuva para abastecimento: o caso da cidade de Belém (PA, Brasil). Estudos Tecnológicos (Online), v. 8, p. 69-80, 2012.

FLORENZANO, Tereza Gallotti. Imagens de satélites para estudos ambientais. São Paulo: Oficina de Textos, 2002.

GOMES, Uende A. Água em situação de escassez: água de chuva para quem? Tese (doutorado) - Universidade Federal de Minas Gerais. Escola de Engenharia. Belo Horizonte, 2012.

GIL, A. Carlos. Como elaborar projetos de pesquisa. 4.ed. São Paulo: Atlas, 2002. 
GONCALVES, C. C.; MENDES, Ronaldo Lopes Rodrigues; COSTA, T. C. D.;OLIVEIRA, D. R. C. Aproveitamento de água da chuva nas ilhas Grande, Murutucu, Urubuoc e Nova - região insular de Belém-Pará. In: VI Encontro Nacional da ANPPAS, 2012, BELÉM. VI Encontro Nacional

GONÇALVES, Cristiane da Costa; MENDES, R. L. R.; COSTA, T. C. D. ;OLIVEIRA, D. R. C . Proposta de Baixo Custo de um Sistema de Aproveitamento de Água da Chuva e Implantação na Ilha Grande - Belém pa. In: 8º Simpósio Brasileiro de Captação e Manejo de Água de Chuva, 2012, Campina Grande - PB. 8o Simpósio Brasileiro de Captação e Manejo de Água de Chuva. Campina Grande, 2012.

LIMA, J. E. F. W. Recursos hídricos no Brasil e no mundo. Embrapa Cerrados, 2001. Disponível em: https://ainfo.cnptia.embrapa.br/digital/bitstream/CPAC-2010/23443/1/doc-33.pdf

MACHADO, Elizabeth. Uma proposta metodológica para elaboração de ATLAS escolares os inicias do ensino fundamental: O exemplo do município de Sorocaba-SP. Tese, USP, 2012. Localizado em

<www.teses.usp.br/teses/.../8/.../2012_ElizabethDeSouzaMachadoHess.pdfde E de Souza Machado-Hess - 2012>

MALVEZZI, Roberto. Semi-árido - uma visão holística. - Brasília: Confea, 2007.

MARCELINO, Emerson Vieira. Mapeamento de áreas susceptíveis a escorregamento no município de Caraguatatuba (SP) usando técnicas de sensoriamento remoto. São José dos Campos. 218p. Dissertação (Mestrado em Sensoriamento Remoto)Instituto Nacional de Pesquisas Espaciais, 2003.

MARTINELLI, Marcelo. As cartografias e os atlas geográficos escolares. Revista da ANPEGE , v. 1, p. 251-260, 2011.

MARTINELLI, Marcelo. Mapas de geografia e geografia temática. São Paulo. Contexto, 2003, p. 15-17.

MEDEIROS, José Simeão de. Bancos de dados geográficos e redes neurais artificiais: tecnologias de apoio à gestão do território. 1999. Tese de Doutorado. Universidade de São Paulo.

MENDES, Ronaldo Lopes Rodrigues; FENZL, Norbert; COSTA, T. C. D. Desenvolvimento de indicadores para o sistema de abastecimento público de água de Belém-PA. Papers do NAEA (UFPA), v. 1, p. 5/301-21, 2012.

MENEZES, Adriany. Paulo Márcio Leal. A questão do processo de ensino e aprendizagem da geografia e o atlas geográfico digital interativo. X Encontro de Geógrafos da América Latina. Universidade de São Paulo. 2005. Disponível em: $<$ http://observatoriogeograficoamericalatina.org.mx/egal10/Nuevastecnologias/Sig/13.pdf >

MESQUITA, Karina. QUALIDADE DA ÁGUA DE CONSUMO NA ILHA DE MOSQUEIRO/PA. Dissertação apresentada para obtenção do grau de Mestre em Engenharia Civil, Instituto Tecnológico, Universidade Federal do Pará. UFPA. Belém, 2012.

Ministério da Saúde (2012). Portaria nº 2.914, de 12 de dezembro de 2011. Dispõe sobre os procedimentos de controle e de vigilância da qualidade da água para consumo humano e seu padrão de potabilidade.

OLIVEIRA, Cêurio de. Curso de cartografia moderna. Rio de Janeiro: IBGE, 1988.

OLIVEIRA, Josiani Cordova et al. MODELAGEM DE DADOS GEOGRÁFICOS: APLICAÇÃO NA GESTÃO DE ÁREAS DE PRESERVAÇÃO PERMANENTE. Revista Geográfica Acadêmica, v. 7, n. 2, p. 22-30, 2013.

PORTARIA, № . 2.914-MINISTÉRIO DA SAÚDE. Dispõe sobre os procedimentos de controle e de vigilância da qualidade da água para consumo humano e seu padrão de potabilidade. BRASIL, 2011

RIGHETTO, Antônio Marozzi; MOREIRA, Lúcio Flávio Ferreira;SALES, TEA de. Manejo de águas pluviais urbanas. Rio de Janeiro: ABES, p. 21-72, 2009. 
RODRIGUES, M. Introdução ao Geoprocessamento. In. SIMPÓSIO BRASILEIRO DE GEOPROCESSAMENTO, 1., 1990, São Paulo. Anais...São Paulo: USP, 1990.

ROSA, Ricardo. MENDES, Ronaldo. COSTA, Tony. Comparativo de custos de utilização de águas subterrâneas e águas pluviais para abastecimento de água - Caso da Ilha Grande em Belém. 2009. Congresso Brasileiro da Água Subterrânea. Associação Brasileira de Águas Subterrâneas. ABAS. São Luís.

SATUSTREGUI, K. U. Desenvolvimento, subdesenvolvimento, mau-desenvolvimento e pós-desenvolvimento: um olhar transdisciplinar sobre o debate e suas implicações. Revista Perspectiva do Desenvolvimento: um enfoque multidimensional, n.1.v1., 2013.

TOMAZ, P. Aproveitamento de Água de Chuva. 2. ed. São Paulo: Navegar. 2003.

VELOSO Nircele. Água da Chuva e Desenvolvimento Local: O caso do abastecimento de água das ilhas de Belém. Dissertação apresentada para obtenção do grau de mestre em Gestão de Recursos Naturais e Desenvolvimento Local na Amazônia. Belém, PA. UFPA, 2012.

VIDAL, R.T., Agua de iluvia - agua saludable- Publicacion del Proyiecto de Apoyo a la Reformma del Sector Salude de Guatemala. "APRESAL" Coemision Europea. Impreso em M'ks Comunicacion. Abril 2000 - República da Guatemala, 2002. Disponível em < biblioteca.usac.edu.gt/tesis/08/08_3073_C.pdf> Acessado em: 26/04/2016.

ZOLET, M. Potencial de aproveitamento de água de chuva para uso residencial na região urbana de Curitiba. Curitiba, 2005. Trabalho de Conclusão de Curso (Graduação em Engenharia Ambiental), Pontifícia Universidade Católica do Paraná, 2005. 